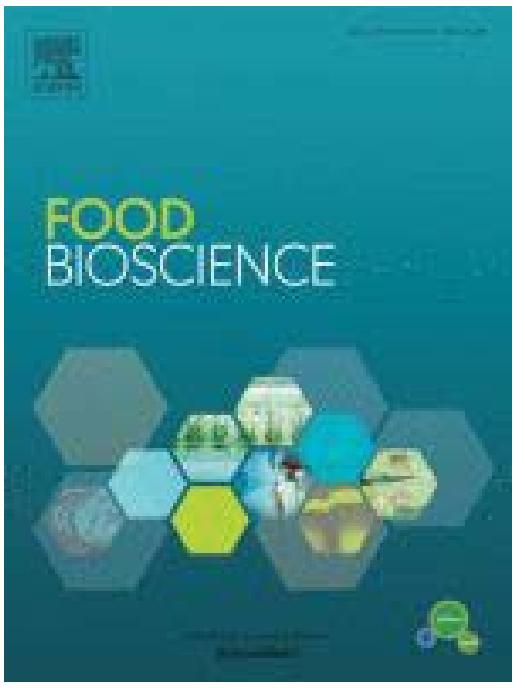




\begin{tabular}{|c|c|c|}
\hline Food Bioscience | & & Submit vour anide $\pi$ \\
\hline 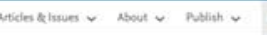 & a smotion & Gude for rutiton $x$ \\
\hline
\end{tabular}

Editors.in.Chief

Fin

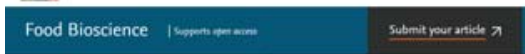

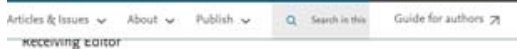

(1)

Associate Editors

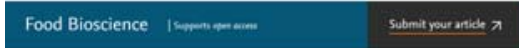

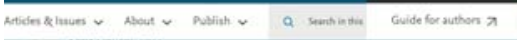

ค

2. John Moveres

P. Fath Omovul, tho

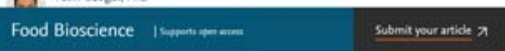

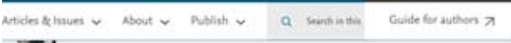

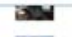

ม

Q. Perg zhou, pho

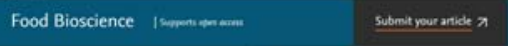

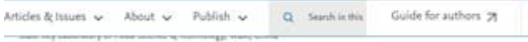

Managing Editor

vie zhow

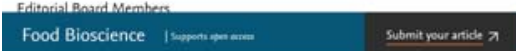

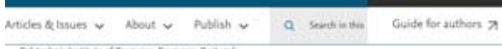

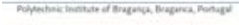

Feng chen

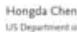

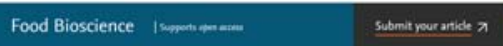

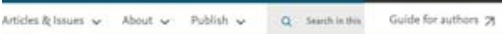

8

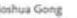

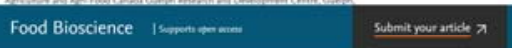

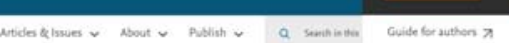

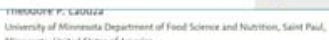

apreng lee

Lin L

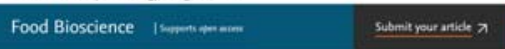

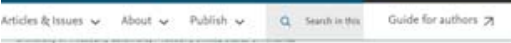

Yostincerimine

Nojan Narbod

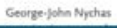

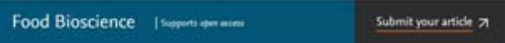

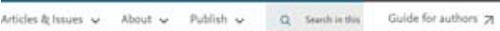

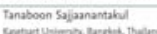

ndenon santino

Feridoon Shatis

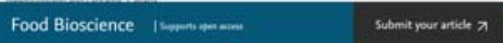

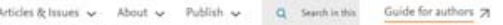

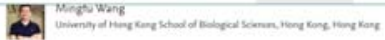

reng $x_{03}$

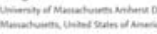

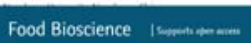

Submit your anide $\pi$

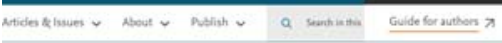

Food Bioscience | Submit pour antich $x$

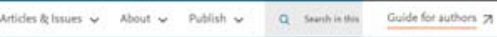

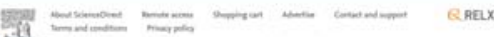

$=$ 

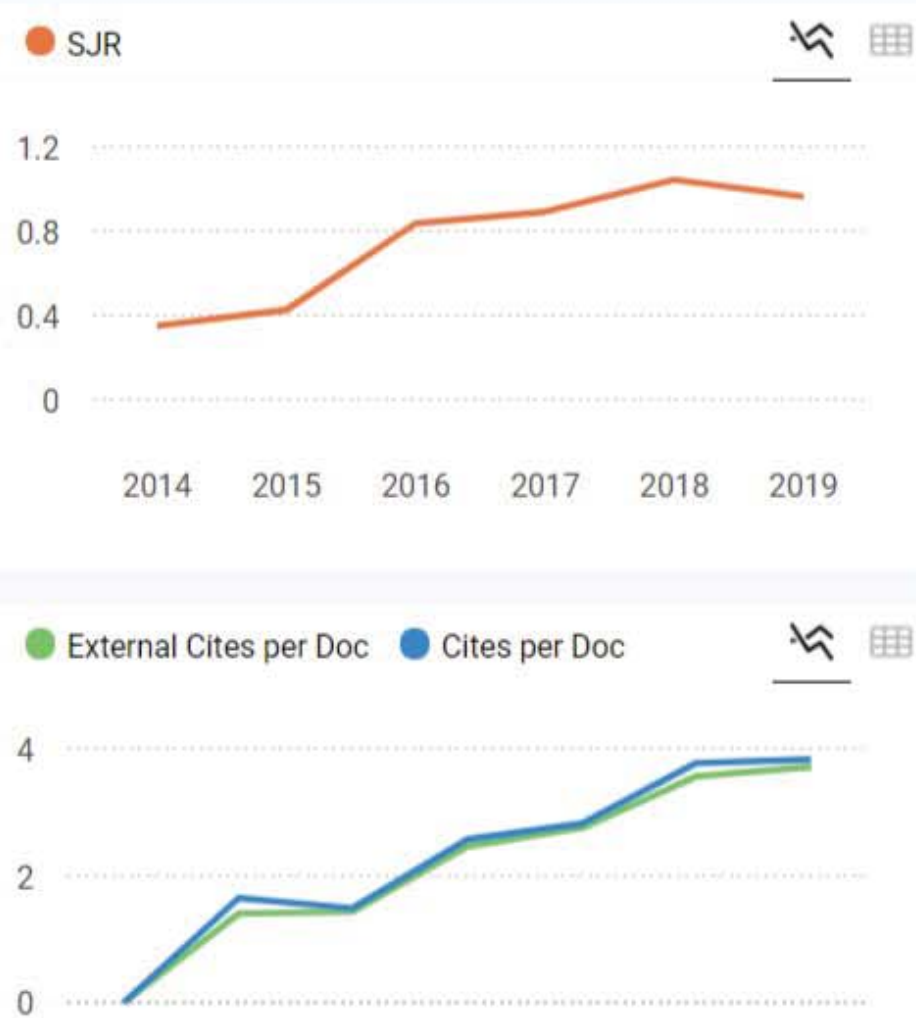

$\begin{array}{lllllll}2013 & 2014 & 2015 & 2016 & 2017 & 2018 & 2019\end{array}$

Citable documents Non-citable documents れ 400

200

0

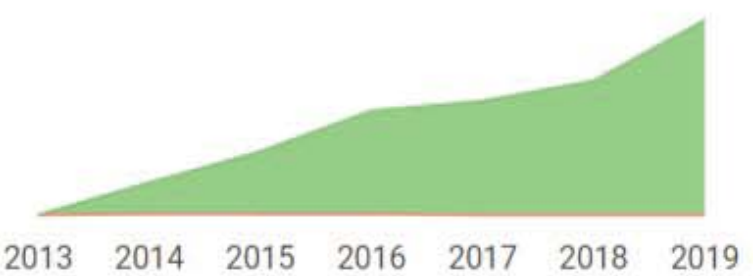

Total Cites Self-Cites

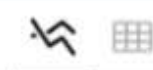

$1 \mathrm{k}$

500

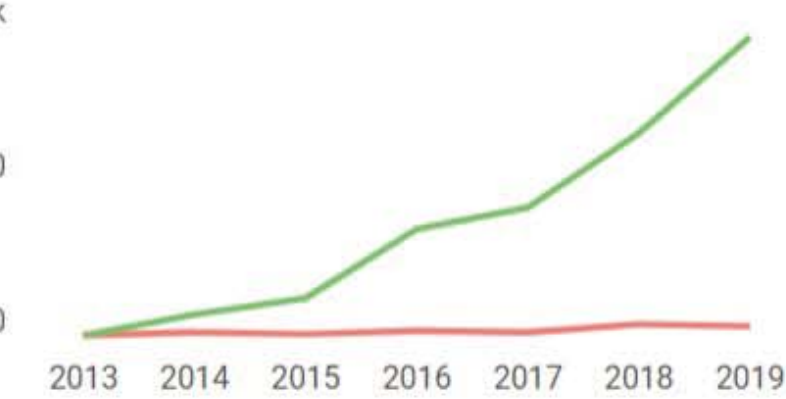

$\%$ International Collaboration

乞

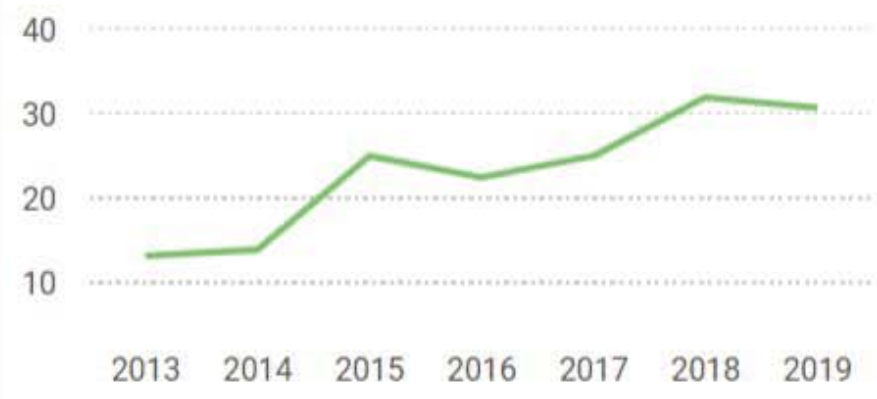

Cited documents Uncited documents

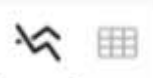
400

200

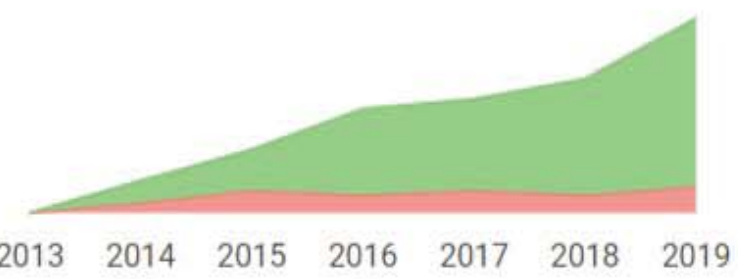

Citations per document

๘

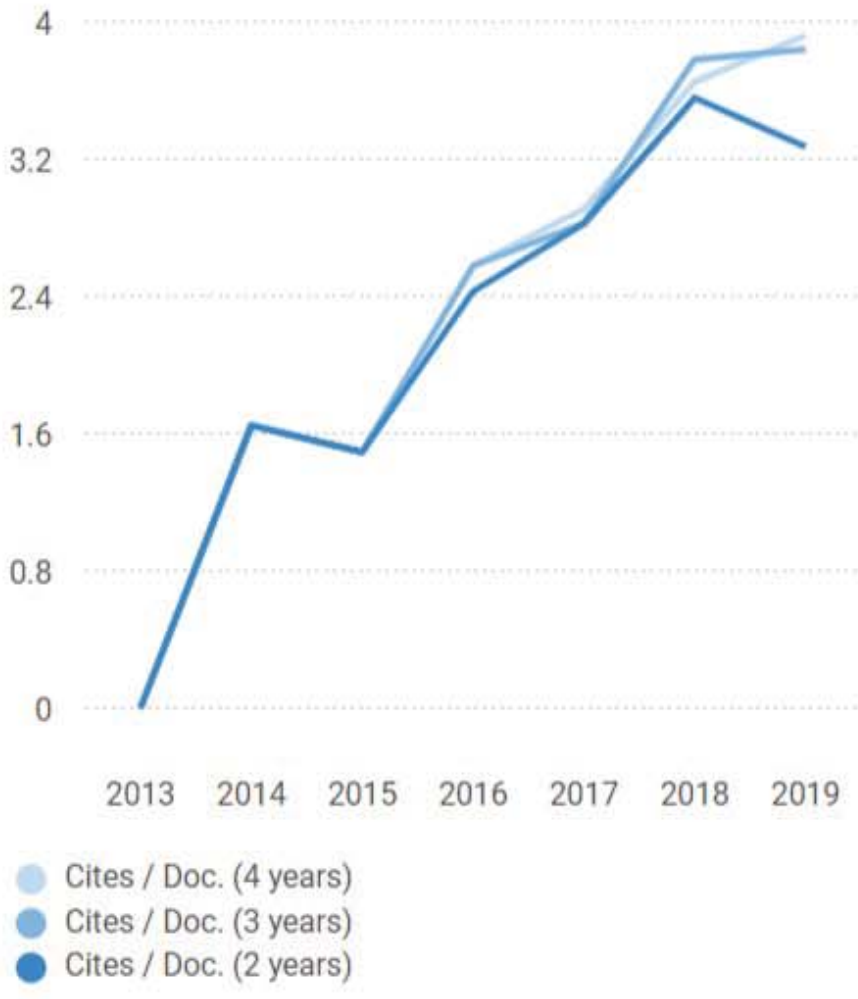

Food Bioscience

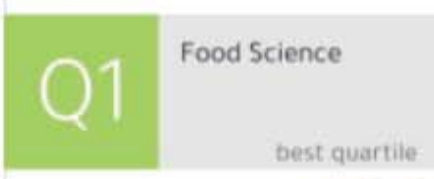

SJR 2019

0.97

powered by scimagojic.com $\leftarrow$ Show this widget in your own website

Just copy the code below and paste within your $\mathrm{html}$ code:

$<$ a href="https://www.scima! 


\title{
Wound healing effects of Plantago major extract and its chemical compounds in hyperglycemic rats
}

\author{
Kartini Kartini ${ }^{\text {a,*, Nina Wati }}{ }^{\text {a }}$, Rabbindra Gustav ${ }^{\text {a }}$, Risa Wahyuni ${ }^{\text {a }}$, Yosua Fernaldi Anggada ${ }^{\text {, }}$ \\ Risna Hidayani ${ }^{\mathrm{a}}$, Antoni Raharjo ${ }^{\mathrm{a}}$, Ridho Islamie ${ }^{\mathrm{b}}$, Sulistyo Emantoko Dwi Putra ${ }^{\mathrm{c}}$ \\ a Department of Pharmaceutical Biology, Faculty of Pharmacy, University of Surabaya, Surabaya, 60293, Indonesia \\ b Department of Clinical and Community Pharmacy, Faculty of Pharmacy, University of Surabaya, Surabaya, 60293, Indonesia \\ ${ }^{c}$ Department of Biology, Faculty of Biotechnology, University of Surabaya, Surabaya, 60293, Indonesia
}

\section{A R T I C L E I N F O}

\section{Keywords:}

Plantago major

Greater plantain

Ursolic acid

Oleanolic acid

Diabetic wound

\begin{abstract}
A B S T R A C T
Impaired wound healing is among the serious complications of diabetes that can lead to amputation and even death. Plantago major has been used empirically to improve wound healing. The main bioactive compounds of $P$. major extracts, ursolic acid (UA) and oleanolic acid (OA), have also been studied for their benefits with nonhyperglycemic wounds. This study was done to examine the in vivo wound healing effects of $P$. major leaf extracts (PMLE), UA, and OA in hyperglycemic rats, to evaluate their in vitro diabetic wound healing activity, and to observe possible dermal irritation after topical application. Wound closure, duration of epithelialization, and histopathological profiles of healed tissue were observed in the hyperglycemic rats with excision wounds for 21 days. An anti-inflammatory test using the NO inhibitory assay, a fibroblast proliferation assay, and a migration assay with high-glucose medium were done to investigate the mechanism of action of the tested samples in wound healing. The acute dermal irritation test followed the international guidelines. PMLE, UA, and OA increased the percentage of wound closure and accelerated wound healing time. PMLE activities were assessed for the inhibition of NO production in the inflammation phase and enhancement of fibroblast proliferation. UA may contribute to this wound healing process through inhibition of NO production, whereas OA through activation of migration of fibroblast cells. Topical applications of PMLE, UA, and OA did not cause acute dermal irritation. PMLE, UA, and OA have the potential to improve wound healing with diabetes conditions.
\end{abstract}

\section{Introduction}

Plantago major or greater plantain is the most widely used species of the genus Plantago and belongs to the Plantaginaceae family. In many parts of the world, P. major is ubiquitous and, therefore, has various local names, including daun sendok in Indonesia (Adom et al., 2017; Gonçalves \& Romano, 2016; Kartini et al., 2017; Samuelsen, 2000). They are wild plants that have good adaptability to diverse conditions in the environment. Nevertheless, to minimize the exploitation of natural resources, prior studies have attempted to optimize its cultivation, harvest, and postharvest processing (Prakash et al., 2011; Zubair et al., 2011). These practices can promote sustainable and efficient production now that there is an increasingly high demand for $P$. major, both in the nutraceutical and pharmaceutical sectors.

Plantago major contains high concentrations of mucilaginous carbohydrates that are active as immunostimulants and antioxidants and are important as excipients in food processing, tablets and emulsions formulations (Akbari et al., 2016; Lukova et al., 2017; Niknam et al., 2020). Its mucilaginous property underlies the use of $P$. major as a nutraceutical, especially to improve intestinal health (Gonçalves \& Romano, 2016; Samuelsen, 2000; Samuelsen et al., 1995). In some regions, fresh leaves of $P$. major are also used as ingredients in salads and soups, and the seeds can also be processed into snacks, cakes, and breads (Gonçalves \& Romano, 2016). The medicinal properties of $P$. major are attributable to its various biologically active compounds such as terpenoids, phenolic acids, flavonoids, alkaloids, and iridoids. It is traditionally used in the treatment of a number of diseases, such as wounds and other skin diseases, infectious diseases, problems concerning the digestive and respiratory organs, reproduction and circulation issues, and tumors, and for pain relief and fever reduction (Adom et al., 2017; Gonçalves \& Romano, 2016; Najafian et al., 2018; Samuelsen, 2000). Many studies have been carried out to confirm these practical applications (Chiang et al., 2002, 2003; Kartini et al., 2014; Kolak et al., 2011; Mansor et al., 2014;

\footnotetext{
* Corresponding author.

E-mail address: kartini@staff.ubaya.ac.id (K. Kartini).
} 


\author{
Abbreviations \\ DFU diabetic foot ulcer \\ HPTLC high performance thin layer chromatography \\ NO nitric oxide \\ OA oleanolic acid \\ OECD Organisation for Economic Cooperation and \\ Development \\ PMLE Plantago major leaves extract \\ UA ursolic acid
}

Ozaslan et al., 2007; Poor et al., 2017).

These lead to the conclusion that $P$. major may have promise for the management of various chronic clinical disorders, including diabetes mellitus and its complications, particularly diabetic foot ulcers (DFU). Abdulghani et al. (2014) found that P. major methanol extracts at 500 and $1000 \mathrm{mg} / \mathrm{kg}$ bw lowered blood glucose levels in streptozotocin-induced diabetic rats. The mechanism underlying this activity was studied by increasing the control of the glycemic mechanism of the remaining pancreatic cells in diabetic rats (Abdulghani et al., 2014; Adom et al., 2017). P. major also has a long history of wound healing. Many countries in Europe, Asia, and the Middle East (e.g., Iran) have long used this herb either for acute or chronic wounds (Adom et al., 2017; Gonçalves \& Romano, 2016; Hosseinkhani et al., 2017; Jarić et al., 2018; Jivad et al., 2016). Moreover, both in vitro and in vivo tests have been done to show the wound healing effect of $P$. major and its constituents, such as UA, OA, and aucubin (Agra et al., 2015; Amini et al., 2010; Kartini et al., 2018a; Moura-Letts et al., 2006; Phipps \& Mahmood, 2006; Velasco-Lezama et al., 2006; Zubair et al., 2012, 2016).

However, there has been no report on $P$. major activity for diabetic wound healing. The wound healing process involves a series of overlapping phases, namely, hemostasis, inflammation, proliferation, and remodeling, that may be inhibited by the presence of oxygen free radicals, microbial infection, and high blood glucose (Houghton et al., 2005; Patel et al., 2019). Chemical or herbal medicines that can modulate one or more of those phases can be examined as candidates for wound healing agents with normal or hyperglycemic conditions. Previous studies showed that $P$. major and its phytochemicals are active anti-inflammatory, antioxidant, and antimicrobial agents (Hussan et al., 2015; Ikeda et al., 2008; Kartini et al., 2014, 2017; Liu, 1995; Mazzutti et al., 2017; Shirley et al., 2017; Stenholm et al., 2013; Vasconcelos et al., 2006). Therefore, this study was intended to determine the in vivo wound healing effects of $P$. major extracts and chemical compounds, namely UA and OA, in hyperglycemic rats (i), to evaluate their in vitro diabetic wound healing activity through the anti-inflammatory process, fibroblast proliferation, and fibroblast migration (ii), and to determine possible dermal irritation after topical application (iii).

\section{Materials and methods}

\subsection{Plant materials and chemicals}

Wholes plants of $P$. major was collected from the cultivation area of the Balai Materia Medica, Batu City, Jawa Timur Province, Indonesia in September 2016 (Global Positioning System (GPS) coordinates $7^{\circ} 52^{\prime} 2.262^{\prime \prime} \mathrm{S} 112^{\circ} 31^{\prime} 11.719^{\prime \prime} \mathrm{E} ; 875 \mathrm{~m}$ above sea level) and promptly transferred within $1 \mathrm{~h}$ to the laboratory. Authentication of the plant was done by the Center for Traditional Medicine Information and Development, University of Surabaya, Surabaya, Indonesia, with accession certificate number: 1212/D.T/IX/2016. UA, OA, alloxan monohydrate, methylthiazolyldiphenyl-tetrazolium bromide (MTT), and hematoxylin-eosin were obtained from Sigma Aldrich Co. (St. Louis, MO, USA), whereas absolute ethanol, toluene, acetone, formic acid,

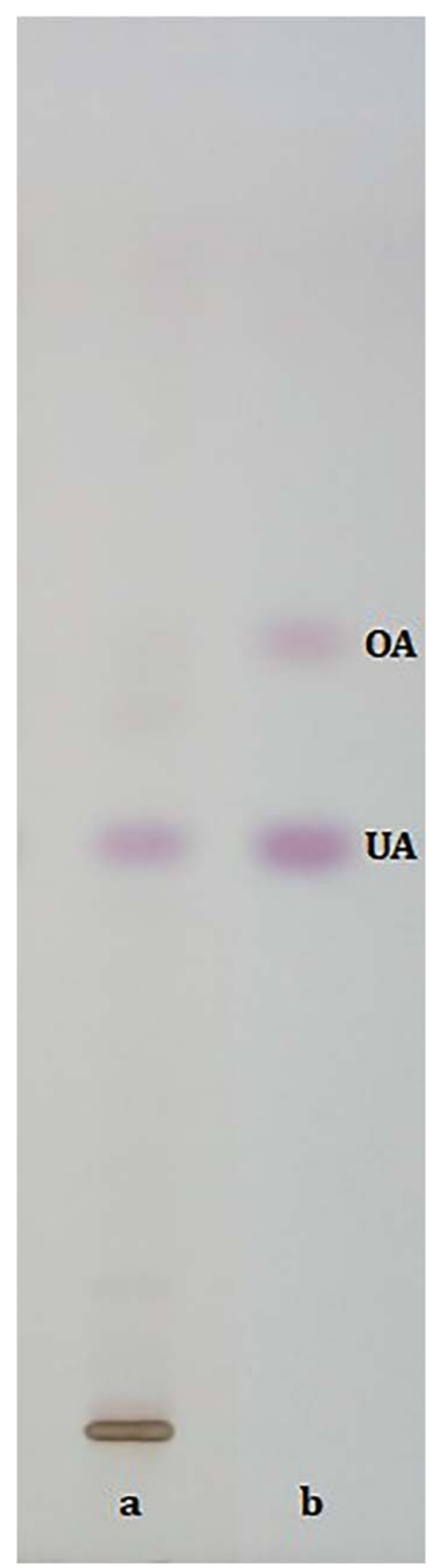

Fig. 1. High performance thin layer chromatography profile of PMLE. Stationary phase: silica gel $60 \mathrm{~F}_{254}$, mobile phase: toluene:acetone:formic acid (78:22:0.15). a: PMLE, b: ursolic acid (UA) - oleanolic acid (OA) standard. 

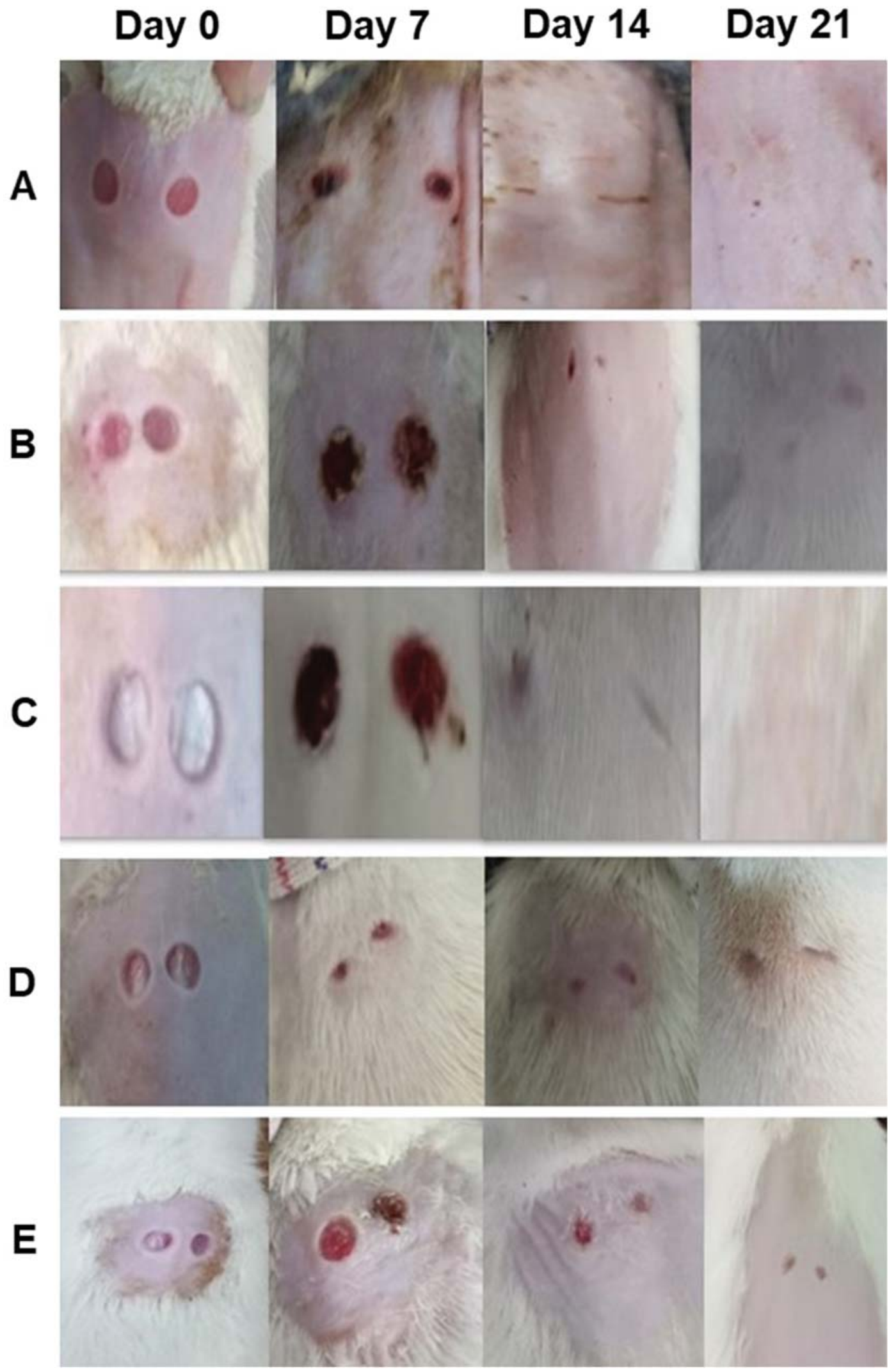

Fig. 2. Wound morphology of hyperglycemic rats from Day 0-21. A: PMLE, B: UA, C: OA, D: Positive control, E: Negative control.

sulfuric acid, methanol, chloroform, iodine, and DMSO were from Merck KGaA (Darmstadt, Germany). Carbomer, sodium hydroxide, methylparaben, propylparaben, and propylene glycol were pharmaceutical grade and obtained from Tristar Chemical Co. (Surabaya, Jawa Timur,

Indonesia). 
Table 1

Effect of gels on wound closure and time of epithelialization.

\begin{tabular}{lllll}
\hline \multirow{2}{*}{ Group } & \multicolumn{2}{l}{ Percentage of wound closure } & \multirow{2}{*}{ Time of epithelialization (day) } \\
\cline { 2 - 3 } & Day 7 & Day 14 & Day 21 & \\
\hline A & $69 \pm 3$ & $98 \pm 1$ & $100 \pm 0$ & $16 \pm 1^{*}$ \\
B & $70 \pm 3$ & $99 \pm 1^{*}$ & $100 \pm 0$ & $15 \pm 1^{*}$ \\
C & $84 \pm 8^{*}$ & $100 \pm 0^{*}$ & $100 \pm 0$ & $12 \pm 1^{*}$ \\
D & $81 \pm 6^{*}$ & $99 \pm 2$ & $100 \pm 0$ & $15 \pm 2^{*}$ \\
E & $67 \pm 2$ & $95 \pm 4$ & $100 \pm 0$ & $19 \pm 1$ \\
\hline
\end{tabular}

Group A: PMLE, B: UA, C: OA, D: Positive control (Mebo $®)$, E: Negative control. Data represent means $\pm S D(n=5)$, ${ }^{*} p<0.05$ against negative control (KruskalWallis, followed by Mann-Whitney test).

\subsection{Preparation of $P$. major extract and determination of $U A$ and $O A$}

The leaves of $P$. major were separated from the other parts of the plant, then air-dried for $120 \mathrm{~h}$, powdered into $2 \mathrm{~mm}$ particles using a household Panasonic MX-J1G blender (Panasonic Corp., Kadoma, Osaka, Japan), and stored at room temperature $\left(31 \pm 2{ }^{\circ} \mathrm{C}\right)$ for a maximum of $12 \mathrm{wk}$ until used. Three hundreds $\mathrm{g}$ of these leaves were macerated with ethanol $(3 \times 800 \mathrm{ml}, 24 \mathrm{~h})$ at room temperature. The extracts were filtered using Whatman ${ }^{\circledR}$ qualitative filter paper grade 1 (Merck) and evaporated under vacuum using a rotavapor R-200 (BÜCHI Labortechnik AG, Flawil, Switzerland) to yield viscous extracts. High performance thin layer chromatography (HPTLC) was done to determine OA and UA as described previously (Kartini et al., 2014). Chromatography was done on a pre-coated HPTLC plate with silica gel 60 $\mathrm{F}_{254}, 0.20 \mathrm{~mm}$ layer thickness (Merck), using toluene:acetone:formic acid (78:22:0.15) as the mobile phase. PMLE and a mixture of OA and UA $(1: 1 \mathrm{w} / \mathrm{w})$ were spotted as $5 \mathrm{~mm}$ bands using a Linomat 5 sample applicator (Camag, Muttenz, Switzerland) and then prederivatized using iodine vapor ( $1 \%$ iodine in chloroform). Development was then carried out using $10 \mathrm{ml}$ of the mobile phase in a twin trough chamber (Camag) previously equilibrated with the mobile phase for $20 \mathrm{~min}$ at room temperature. Following development, the plate was dried in a fume hood and subjected to derivatization by spraying the plate with $5 \%$ sulfuric acid in methanol and then heating at $120^{\circ} \mathrm{C}$ for $3 \mathrm{~min}$. The chromatogram was obtained using Reprostar 3 documentation densitometry (Camag) with a VH-C20 3CCD color video camera (Hitachi Denshi Ltd., Shinjuku City, Tokyo, Japan).

\subsection{Preparation of the gel dosage form}

P. major leaf extract (PMLE), UA, and OA were formulated into gel dosage forms as described previously using carbomer, sodium hydroxide, methylparaben, propylparaben, and propylene glycol (Kartini, et al., 2018). Carbomer ( $2 \mathrm{~g}$ ) was dispersed over $40 \mathrm{ml}$ water, stirred (1000 rpm) using a high shear mixer-HSM 2003 SV/DV (CKL Multimix (M) Sdn Bhd, Puchong, Selangor Darul Ehsan, Malaysia) while adding $1 \%$ sodium hydroxide gradually until it formed a gel. PMLE (5 g), UA (15 mg), or OA (15 mg) were dissolved in $2 \mathrm{ml}$ ethanol. Methyl paraben (180 $\mathrm{mg}$ ) and propyl paraben $(20 \mathrm{mg}$ ) were mixed and dissolved in propylene glycol $(16 \mathrm{~g})$. These two solutions were then mixed and poured into the gel with $100 \mathrm{~g}$ water and stirred until homogeneous. The gels were administered up to $0.5 \mathrm{~g} /$ test animals. Every $0.5 \mathrm{~g}$ PMLE gel contained $25 \mathrm{mg}$ extract, whereas $0.5 \mathrm{~g}$ UA or OA gels contained $75 \mu \mathrm{g}$ of the respective active compounds.

\subsection{In vivo wound healing assay}

Male Wistar rats (180-200 g) were from the Integrated Research and Testing Laboratory, Gadjah Mada University, Yogyakarta, Indonesia and housed at room temperature, $70 \% \mathrm{RH}$, and a $12 \mathrm{~h}$ light-dark cycle. These test animals were put in plastic cages ( 1 rat/cage) and fed with a standard diet (water max. $13 \%$, crude protein $21-23 \%$, fat min. $5 \%$, fiber max. $5 \%$, ash max. $7 \%$, calcium min. $0.9 \%$, and phosphorus min $0.6 \%$ ), given water ad libitum, and acclimatized for $2 \mathrm{wk}$ before the experiment. All handling procedures were according to the institutional rules on animal experiments (approval No: 721-KE; dated June 15, 2017). Before the induction of hyperglycemia, test animals were weighed, their blood was collected from the tail vein, and the fasting blood glucose levels were measured. Then, they were intraperitoneally injected with a single dose of alloxan monohydrate $(160 \mathrm{mg} / \mathrm{kg} \mathrm{bw})$ in normal saline. Two days later, the fasting blood glucose levels were measured to confirm their hyperglycemic status. Hyperglycemia was indicated if the random blood glucose levels were $\geq 200 \mathrm{mg} / \mathrm{dl}$.

Hyperglycemic rats were intraperitoneally anesthetized with ketamine $\mathrm{HCl}$ (Ketalar ${ }^{\circledR}$, Pfizer Indonesia, Jakarta, Indonesia) at $100 \mathrm{mg} / \mathrm{kg}$ bw. An excision wound was induced on the dorsal area of the animals using a biopsy punch from Medax Srl Unipersonale (San Possidonio, MO, Italy) with a diameter of $5 \mathrm{~mm}$. Test animals were then divided into 5 groups, each consisting of 5 rats. Three groups were treated with PMLE, $\mathrm{UA}$, and OA gels, respectively; whereas two other groups were treated with positive and negative control, respectively. A commercially available gel product containing Copitidis Rhizoma, Phellodendri chinensis Cortex, and Scutellariae Radix was used as a positive control (Mebo ${ }$, from Shantou MEBO Pharmaceutical Co., Ltd. (Shantou, Guangdong, China)), while the gel without active ingredient was applied as a negative control. All treatments were carried out topically once daily. Parameters of the in vivo wound healing were the percentage and time of wound closure. Wound diameter was measured using a digital caliper (resolution $0.01 \mathrm{~mm}$ ) on Day 0, 7, 14, and 21. The percentage of wound closure was determined using the following equation:

$\left(\left(D_{1}-D_{2}\right) / D_{1}\right) \times 100$

where $\mathrm{D}_{1}=$ the largest wound diameter (on Day 0 ), and $\mathrm{D}_{2}=$ wound diameter on the day of observation. Healing time was measured as the

Table 2

Effect of gels on wound healing phase on Day 21.

\begin{tabular}{ll}
\hline Group & Healing score \\
\hline A & $2.2 \pm 0.3$ \\
B & $2.7 \pm 0.0^{*}$ \\
C & $3.0 \pm 0.7^{*}$ \\
D & $3.3 \pm 0.1^{*}$ \\
E & $2.0 \pm 0.0$ \\
\hline
\end{tabular}

Group A: PMLE, B: UA, C: OA, D: Positive control (Mebo $\left.{ }^{\circledR}\right)$, E: Negative control. Data represent the means $\pm \mathrm{SD}(\mathrm{n}=3),{ }^{*} \mathrm{p}<0.05$ against negative control (Kruskal-Wallis, followed by MannWhitney test).

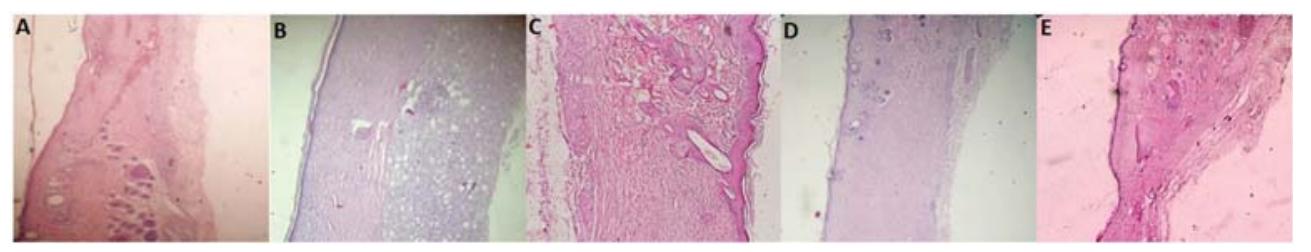

Fig. 3. Histological profiles of healing tissue on Day 21. A: PMLE, B: UA, C: OA, D: Positive control, E: Negative control. 
a

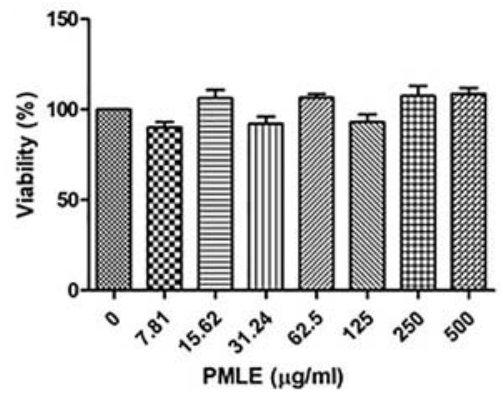

b

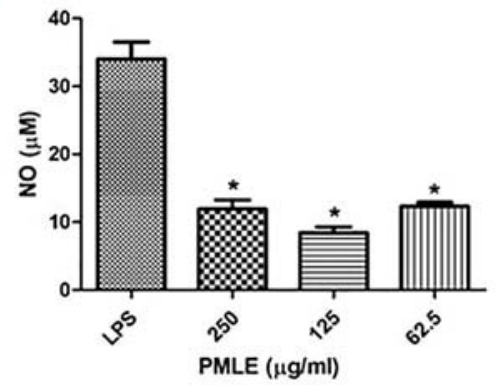

C

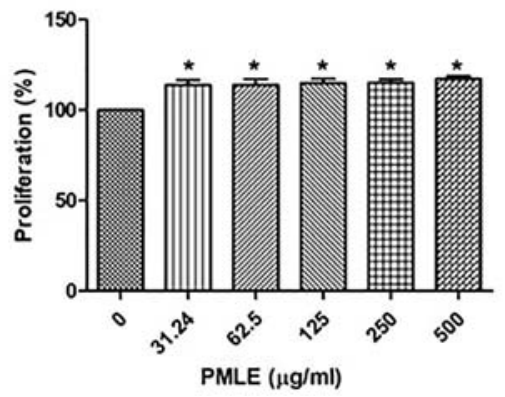

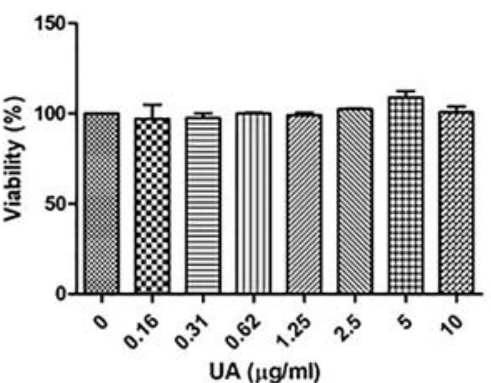
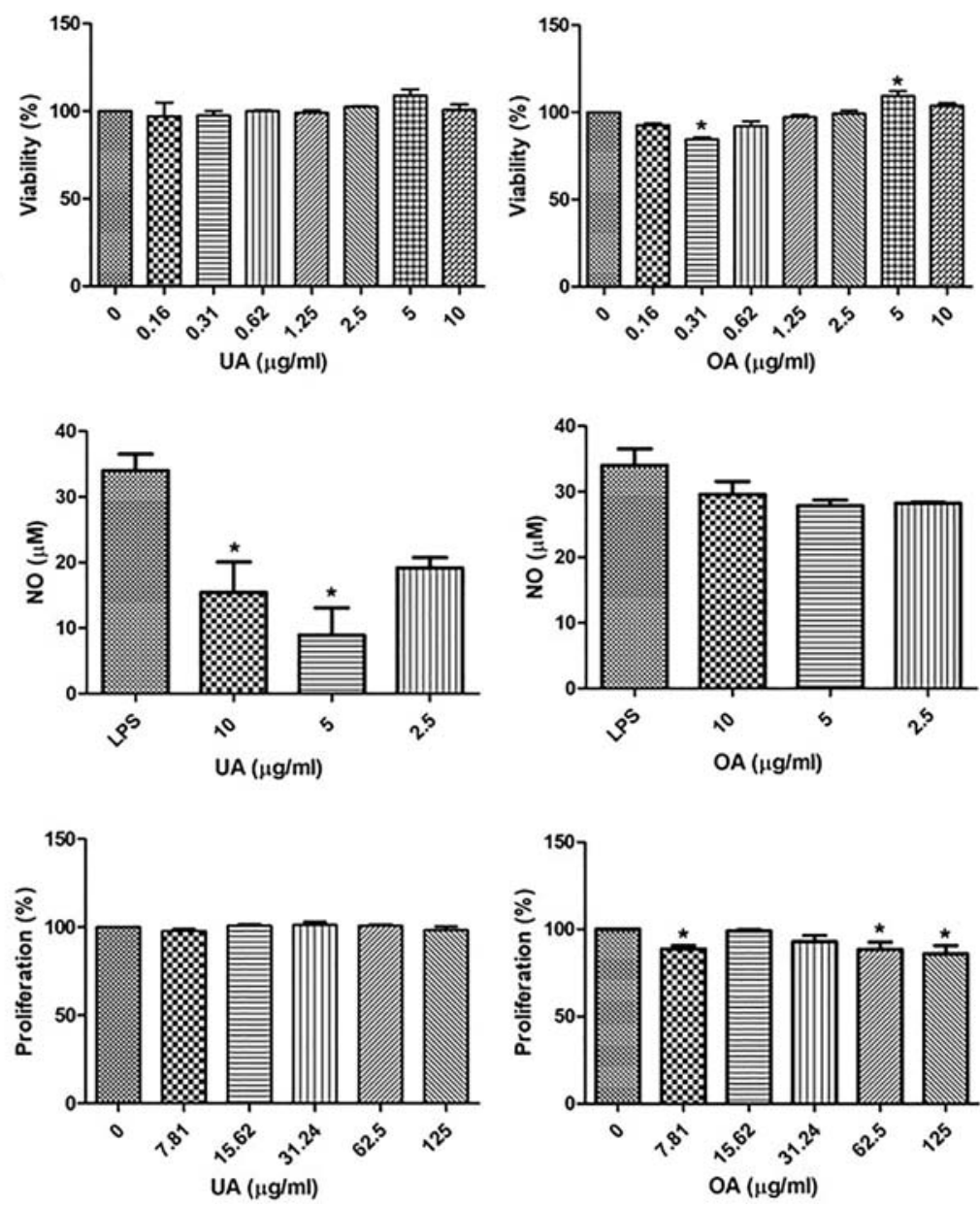

Fig. 4. The effects of PMLE, UA, and OA on the viability of the RAW 264.7 cell line (a), NO production of RAW 264.7 cell line (b), and proliferation of NIH/3T3 fibroblast cells. Data are expressed as mean $\pm \mathrm{SD}(\mathrm{n}=3)$, * $\mathrm{p}<0.05$ against control (one-way ANOVA, followed by Tukey's multiple comparison test).

day when the wound closed fully. Also, healing tissues were collected for a histopathological study on Day 21, in which skin tissues were fixed in $10 \%$ formalin, sliced using an automatic rotary microtome (Thermo Fisher Scientific, Waltham, MA, USA) and prepared on a glass slide, stained with hematoxylin-eosin, and then observed under a light microscope (Olympus Corp., Shinjuku City, Tokyo, Japan). Histopathological study was done to evaluate the condition of healed tissue by observing the presence of inflammatory cells, angiogenesis, fibrosis, fibroblasts, and collagen, on which a score (0-4) of each sample was based. Score 0 means the wound was still open. Score 1 indicated the presence of bleeding $(++)$, inflammation $(++)$, angiogenesis $(++)$, and epithelialization (-); while at score 2, there were signs of inflammation $(+)$, angiogenesis $(+)$, epithelialization $(+)$, and fibrosis $(+)$. Score 3 or early remodeling was represented by the presence of fibroblasts and collagen $(+)$, as well as epithelialization $(+)$; and score 4 or the complete remodeling phase was the formation of collagen $(++)$ and epithelialization $(++)$.

\subsection{In vitro wound healing assay}

\subsubsection{Nitric oxide (NO) inhibitory assay}

The in vitro anti-inflammatory test was done following the method used in a previous study (Tam et al., 2011). RAW264.7 cells (mouse macrophage, ATCC ${ }^{\circledR}$ TIB-71 ${ }^{\mathrm{TM}}, 4 \times 10^{5} /$ well, counted using a counting chamber with v-slash (Paul Marienfeld GmbH \& Co. KG, Lauda-Königshofen, Germany)) were seeded in a 24-well plate overnight. The cells were provided by the Parasitology Laboratory, Medical
Faculty, Gadjah Mada University. PMLE, UA, or OA were added at various concentrations together with $0.1 \mu \mathrm{g} \mathrm{LSS} / \mathrm{ml}$ of the medium and incubated for $24 \mathrm{~h}$. The cell culture supernatant was taken out and added into Griess Reagent (Promega Corp., Madison, WI, USA) at a 1:1 ratio in a 96-well plate, followed by incubation in the dark for $10 \mathrm{~min}$. The absorbance was measured at $540 \mathrm{~nm}$ using a Bio-Rad Benchmark microplate reader (Bio-Rad Laboratories Inc., Hercules, CA, USA). The $\mathrm{NaNO}_{2}$ was used to prepare a standard curve and linear regression equation.

\subsubsection{Fibroblast proliferation assay}

The procedures used for this assay were according to the method described previously, with a slight adjustment (Tam et al., 2011). NIH/3T3 cells (mouse fibroblasts, ATCC ${ }^{\circledR}$ CRL- $1658^{\text {TM}}$; provided by the same parasitology laboratory) were seeded at $10^{3}$ cells/well in a 96-well plate in high-glucose DMEM (4500 mg/1; Fisher Scientific International Inc., Waltham, MA, USA). Then, the cells were exposed to different concentrations of PMLE, UA, and OA for $48 \mathrm{~h}$ at $37^{\circ} \mathrm{C}$. MTT solution (5 $\mathrm{mg} / \mathrm{ml}$ ) in PBS (Fisher Scientific) was added to the medium in each well, and the plate was then incubated at $37{ }^{\circ} \mathrm{C}$ for $4 \mathrm{~h}$. All medium was then removed and replaced with DMSO. The optical density was measured at $540 \mathrm{~nm}$ to determine the relative amounts of viable cells and expressed as the percentage of control samples without treatment.

\subsubsection{Migration assay}

This test, which followed Tam et al. (2011) with adjustment for the type of cell (Tam et al., 2011), was started by seeding rat gingival 

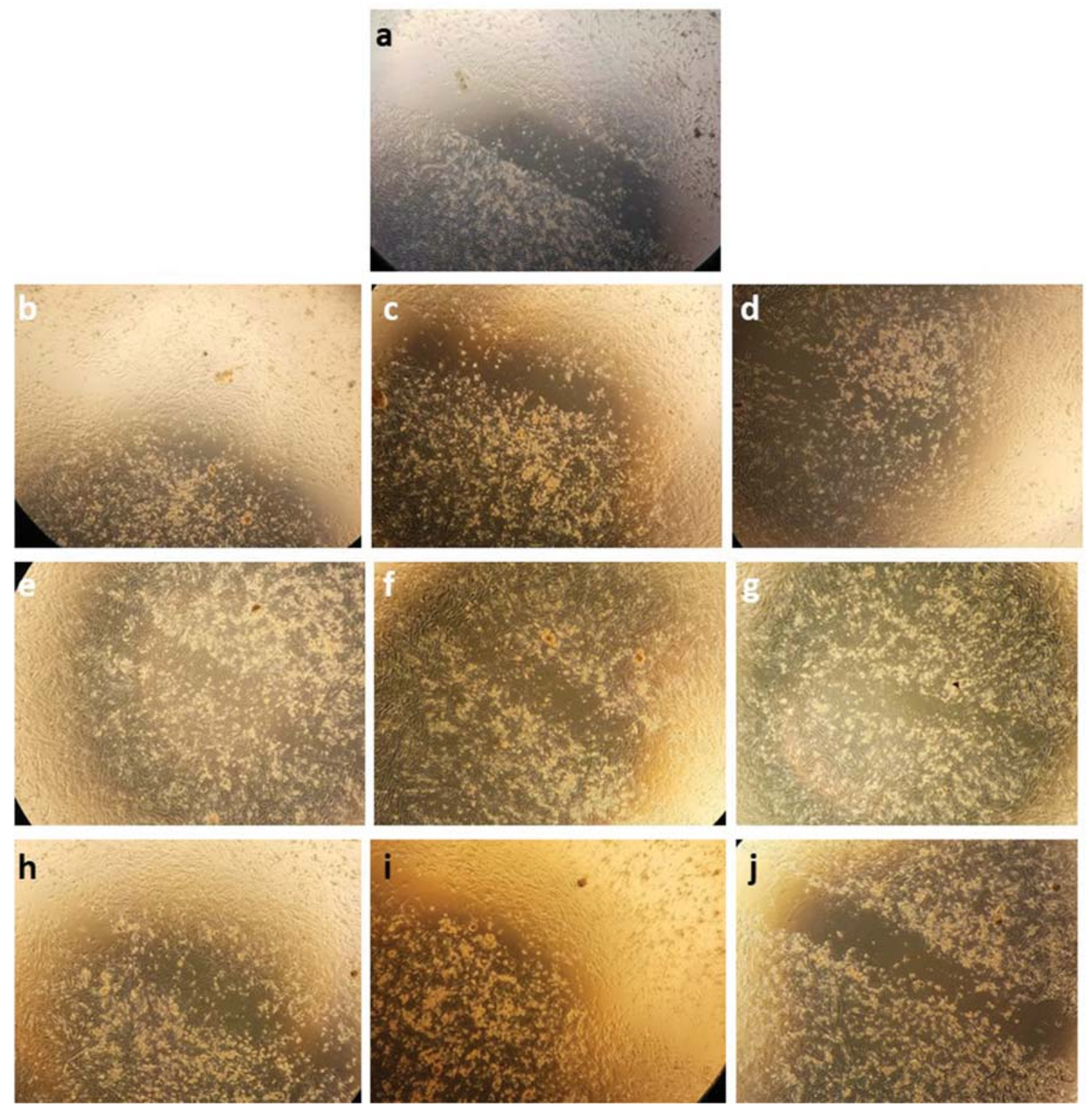

Fig. 5. Representative microphotograph of gingival fibroblast cells before the addition of the test samples (a) and after $24 \mathrm{~h}$ of incubation. b, c, d were induced with PMLE 250, 500, $1000 \mu \mathrm{g} / \mathrm{ml}$, respectively; e, f, g with UA 25, 50, $100 \mu \mathrm{g} / \mathrm{ml}$, respectively; h, i, j with OA 25, 50, $100 \mu \mathrm{g} / \mathrm{ml}$, respectively.
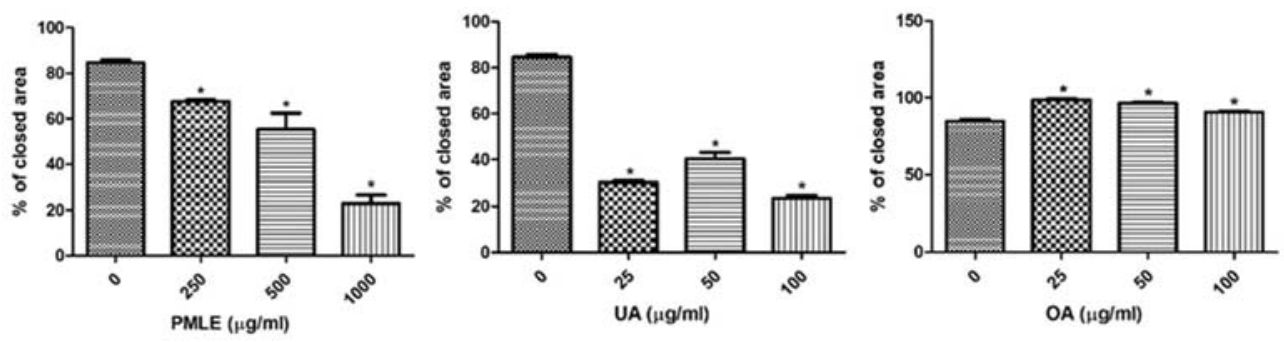

Fig. 6. The effects of PMLE, UA, and OA on closed areas observed in the gingival fibroblast migration test on rats. Data are expressed as mean \pm SD ( $n=3$ ), * $<<0.05$ against control (one-way ANOVA, followed by Tukey's multiple comparison test).

fibroblast cells at $10^{5}$ cells/well in a 24 -well plate in high-glucose DMEM. These cells were obtained from the Institute of Tropical Disease, Airlangga University (Surabaya, Indonesia). Cells were incubated for $24 \mathrm{~h}$ at $37{ }^{\circ} \mathrm{C}$ in a $5 \% \mathrm{CO}_{2}$ humidified incubator. Cells were then observed under a microscope to ensure that they had adhered to the well and achieved a confluent state. Fibroblast cells in the well were then scratched in one direction using a $1000 \mu \mathrm{l}$ pipette tip, then observed under a light microscope, and photographs were taken. A series of concentrations of PMLE, UA, or OA solutions were added into each well, then incubated overnight. The results were observed under a light microscope and photographed. The photographs were compared and analyzed using the TScratch program (CSElab, Zurich, Switzerland) to 


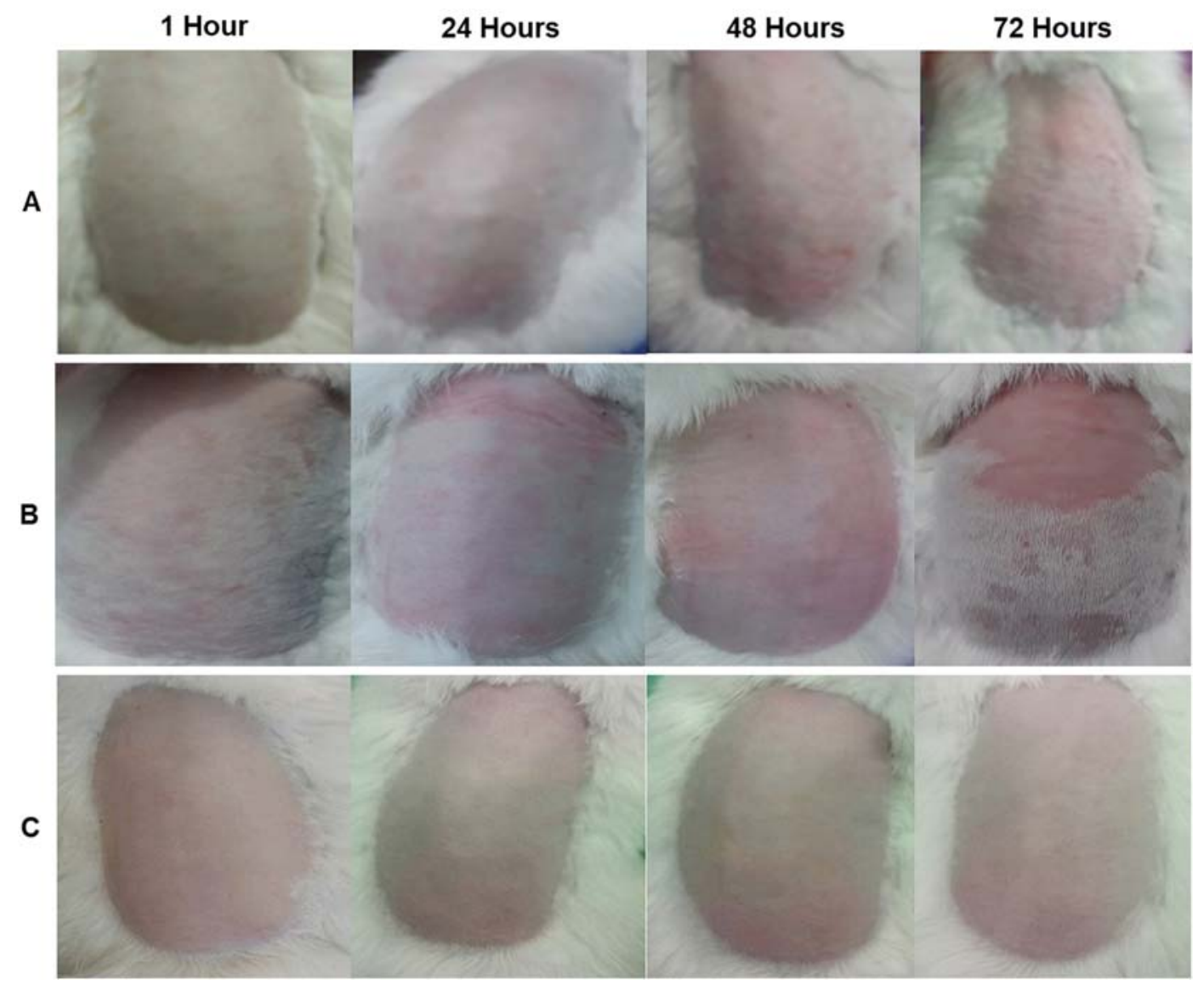

Fig. 7. The results of the 72-h acute irritation dermal test. A: PMLE, B: UA, C: OA.

determine the migration. This program measures open areas in the images. Percentage of the closed area before and after treatments were then calculated. An increase of the percentage of closed area indicated the migration.

\subsection{Acute dermal irritation assay}

The test followed the method recommended in the Organisation for Economic Cooperation and Development Guideline No. 404 (2015) (OECD, 2015). Healthy male albino rabbits aged 8-9 months (adult) and weighing around $1.8-2.3 \mathrm{~kg}$ were used as test animals. They were individually housed and acclimatized to the experimental conditions for $1 \mathrm{wk}$, fed with conventional laboratory diets (crude protein 18-19\%, crude fiber $13 \%$, fat $5-6 \%$, calcium $0.9 \%$, phosphorous $0.7 \%$, water $11 \%$, flumequine antibiotic and vitamins), and given ad libitum access to drinking water. Approximately $24 \mathrm{~h}$ before the test, fur was removed by carefully clipping the dorsal area of the trunk of the animals using an electrical hair clipper. The test samples were applied to a small area $( \pm 6$ $\mathrm{cm}^{2}$ ) of skin and covered with a gauze pad, which was held in place with non-irritating tape (Beiersdorf Indonesia, Malang, Jawa Timur, Indonesia). For the initial test, one animal was used. Three test patches were applied sequentially to the animal. The first patch was removed after $3 \mathrm{~min}$. If there was no apparent serious skin reaction, a second patch was applied at a different site and removed after $1 \mathrm{~h}$. If the observations at this stage indicated that exposure could humanely be allowed to extend to $4 \mathrm{~h}$, a third patch was applied and removed after 4 $\mathrm{h}$, and the response was graded. If a corrosive effect appeared after any of the three sequential exposures, the test was immediately terminated. However, if no corrosive effect (irritation) was formed after the last patch was removed, the animal was observed for 14 days, unless corrosion developed at an earlier point of time. If there was no serious skin reaction in the initial test, the irritant or negative response was confirmed using up to two additional animals, each with one patch, for an exposure period of $4 \mathrm{~h}$. The animals were observed for 14 days after the removal of patches. All animals were examined for erythema and oedema, and the responses were scored at $\mathrm{h} 1,24,48$, and 72 after patch removal. Score 0 was indicated by no erythema and no oedema; score 1 was very slight erythema and oedema; score 2 was well defined erythema and slight oedema; score 3 was moderate to severe erythema and moderate oedema; and score 4 was severe erythema and oedema.

\subsection{Statistical analysis}

All data were reported as mean $\pm \mathrm{SD}$, then analyzed by descriptive statistics, one-way ANOVA and Tukey's multiple comparison test in the statistical program, GraphPad Prism (GraphPad Software Inc., San Diego, CA, USA, Windows Version 5.01). If the data did not meet the requirements of a parametric statistical test, then they were processed with the Kruskal-Wallis test and the Mann-Whitney post hoc test. p < 0.05 distinguished a statistically significant difference.

\section{Results and discussion}

\subsection{High performance thin layer chromatography of PMLE}

The presence of UA and OA in the PMLE was identified using HPTLC (Fig. 1). The chromatogram showed that PMLE contains UA, but the presence of OA cannot be detected. This is consistent with the previous studies which showed that OA was present in the petiole, seed, and aerial parts, but not in the leaves and roots (Kartini et al., 2014, 2017). 


\subsection{In vivo wound healing}

The wound healing efficacy of PMLE, UA, and OA was investigated from the wound closure, time of epithelialization, and gross examination for 21 days. Also, at the end of the test, the histopathological profile of healed tissue was documented. Wound closure and time of epithelialization were examined to determine the rate of reduction of the unhealed area during the healing process. A faster rate of wound closure indicates a better efficacy. The shrinking of the wound area in different groups of treated animals over 21 days due to PMLE, UA, and OA is shown in Fig. 2 and Table 1.

Overall, the topical application of PMLE and its chemical constituents (UA and OA) increased wound closure significantly ( $\mathrm{p}<0.05$ ), particularly on Day 7 and 14. On Day 21, although complete wound closure was observed in all groups, no significant differences were detected. Table 1 also shows that time of epithelialization of the groups treated with PMLE and UA was not significantly different from that of the positive control (Mebo®). It suggested that PMLE and UA are as active as the positive control. Animals treated with OA gel showed the fastest epithelialization, indicating that OA had higher efficacy for wound healing with hyperglycemic conditions. A previous study on wound healing in mice with normal conditions confirmed that OA is $42.9 \%$ faster and more effective than the placebo, and at the dose of 40 $\mu \mathrm{g} / \mathrm{g}$ bw, it produces the highest wound healing effect (Moura-Letts et al., 2006). Histological profiles of healing tissue (Fig. 3 and Table 2) show that on Day 21, animals treated with OA and positive control gels had started the remodeling phase, approaching complete remodeling. However, groups treated with PMLE, UA, and negative control were still in phase 2 and progressing to early remodeling, as characterized by ongoing angiogenesis and inflammation, and early development of fibrosis and epithelialization. These results were consistent with OA producing the best outcome in wound closure and the fastest epithelialization.

\subsection{Effect of PMLE, UA, OA on NO production by RAW264.7 cells}

Repair needs the coordination of various cells, growth factors, and cytokines. In diabetic patients, the normal wound healing process is interrupted by high blood glucose. Diabetic wounds show a persistent inflammatory phase resulting in the inhibited formation of mature granulation tissue and reduction in wound tensile strength, which may be caused by ischemic damage to blood vessels (Patel et al., 2019).

The anti-inflammatory activity of PMLE, UA, and OA was investigated using the NO inhibition test on RAW264.7 macrophage cells. The cells were cultured in high-glucose medium to mimic a diabetic condition. Apart from RAW264.7, macrophage-like cells such as THP-1 can also be used to evaluate in vitro anti-inflammatory activity. These monocytes will differentiate into macrophage after induction with phorbol 12-myristate 13-acetate (PMA) (Chanput et al., 2014). The use of RAW264.7 cells was preferred since this research did not need to differentiate the cells. Bacterial infections or immunological stimuli such as LPS induce macrophages to release a high concentration of NO, which is potentially cytotoxic and can destroy the surrounding cells and tissues. Before the NO inhibition test, the effects of PMLE, UA, and OA on cell viability was evaluated to determine the appropriate concentration for the NO inhibition tests (Fig. 4a). The viability of RAW264.7 cells did not significantly decrease after the addition of PMLE, UA, and OA at up to 500,10 , and $10 \mu \mathrm{g} / \mathrm{ml}$, respectively. These results indicated that all samples at these concentrations were non-toxic to the cells and did not affect the regular cellular activity.

After treatment with PMLE, UA, and OA, the NO concentration in the cell culture media was measured using the Griess Reaction. All concentrations of PMLE and UA suppressed the NO production in RAW264.7 cells significantly after LPS induction (Fig. 4b), indicating that PMLE and UA have anti-inflammatory properties. OA (2.5-10 $\mu \mathrm{g}$ / $\mathrm{ml}$ ) also inhibited the production of NO; however, the reduction was not significantly different from that of the control. On the other hand, previous research with normal media showed that OA inhibited some inflammatory mediators, such as COX-2, TNF- $\alpha$, IL- $1 \beta$, IL-6, and IFN- $\gamma$ (Kartini et al., 2014, 2017; Ringbom et al., 1998; Stenholm et al., 2013). Therefore, further studies are needed to confirm whether or not OA is an active anti-inflammatory agent with hyperglycemic conditions using these other inflammatory mediators.

\subsection{Effects of PMLE, UA, and OA on NIH/3T3 fibroblast proliferation}

The wound healing cascade is a complex interaction of cellular and biochemical actions that differentiates into several phases, from healing to structural and functional integrity restoration to regain the strength of injured tissues. Fibroblast proliferation is one crucial step in tissue regeneration. A series of PMLE, UA, and OA concentrations were tested at the proliferation phase using NIH/3T3 fibroblast cells. Fig. 4c shows that PMLE at $31-500 \mu \mathrm{g} / \mathrm{ml}$ increased fibroblast proliferation, but the opposite was true for UA and OA administered at 7.81-125 $\mu \mathrm{g} / \mathrm{ml}$. These results were consistent with Kuonen et al. that the lipophilic extract of Viscum album L. and oleanolic acid did not produce any proliferationstimulating effects in $\mathrm{NIH} / 3 \mathrm{~T} 3$ fibroblast cells at any concentration (0.01-100 and 0.001-10 $\mu \mathrm{g} / \mathrm{ml}$, respectively) (Kuonen et al., 2013). Therefore, UA and OA probably contributed to diabetic wound healing through other mechanisms.

\subsection{Effects of PMLE, UA, and OA on fibroblast migration}

Angiogenesis, another process contributing to wound healing, is important until the terminal stages of healing. Its mechanism involves proliferation, migration, and remodeling of endothelial cells, followed by subsequent tube formation. The effects of PMLE, UA, and OA on the migration activity were assessed using gingival fibroblast cells that had been isolated from the rats. Fig. 5 shows the photograph of the scratched cells before the addition of the samples. This figure also shows the open area of cells at the bottom of wells after incubation with serial concentrations of PMLE, UA, and OA. Fig. 6 shows that all concentrations of PMLE and UA did not increase cell migration; on the other hand, open areas were reduced as OA concentration increased. The percentage of closed area in treated cells to the control cells indicates the level of cell migration activity. Fig. 6 shows that OA $(25-100 \mu \mathrm{g} / \mathrm{ml})$ can increase the migration of rat gingival fibroblast cells.

\subsection{Acute dermal irritation test}

The results of the acute dermal irritation test of PMLE, UA, and OA gels are shown in Fig. 7. No dermal responses, including erythema or oedema, were found in animals treated with either UA or OA gels. In the group treated with PMLE gel, some rabbits showed erythema after 48 and $72 \mathrm{~h}$. However, this is still included in the nonirritant category (Banerjee et al., 2013).

\section{Conclusions}

Plantago major leaf extracts and its phytochemicals (UA and OA) can increase the percentage of wound closure and accelerate wound healing time in hyperglycemic rats. The extent of these activities was determined using the inhibited NO production in the inflammation phase and enhanced fibroblast proliferation. While UA contributed to the wound healing process by inhibiting NO production, OA showed the same function by activating fibroblast cell migration. Topical applications of $P$. major leaf extracts, UA, and OA in gel dosage forms did not cause acute dermal irritation. This study showed that $P$. major leaf extracts, $\mathrm{UA}$, and OA acid have the potential to improve wound healing with diabetes conditions. 


\section{Author statement}

This study was designed, directed and coordinated by Kartini Kartini, Ridho Islamie and Sulistyo Emantoko Dwi Putra for all aspects of the project. Nina Wati, Rabbindra Gustav, and Risa Wahyuni partly contributed to the in vivo wound healing assay, whereas Yosua Fernaldi Anggada, Risna Hidayani, and Antoni Raharjo involved in the in vitro assay and safety evaluation. Ridho Islamie and Sulistyo Emantoko Dwi Putra suggested and commented on the design of the experiments. The manuscript was written by Kartini Kartini and commented by all authors. All authors have read and approved the final version of the manuscript.

\section{Declaration of competing interest}

The authors confirm that they have no conflicts of interest with respect to the work described in this manuscript.

\section{Acknowledgements}

This research was supported by the Indonesian Ministry of Research, Technology, and Higher Education (grant number 017/SP-Lit/LPPM01/Ristekdikti/FF/III/2018).

\section{References}

Abdulghani, M. A., Hamid, I., Al-Naggar, R. A., \& Osman, M. T. (2014). Potential antidiabetic activity of Plantago major leaves extract in streptozocin-induced diabetic rats. Research Journal of Pharmaceutical, Biological and Chemical Sciences, 5(2), 896-902.

Adom, M. B., Taher, M., Mutalabisin, M. F., Amri, M. S., Kudos, M. B. A., Sulaiman, M. W. A. W., Sengupta, P., \& Susanti, D. (2017). Chemical constituents and medical benefits of Plantago major. Biomedicine \& Pharmacotherapy, 96, 348-360.

Agra, L. C., Ferro, J. N., Barbosa, F. T., \& Barreto, E. (2015). Triterpenes with healing activity: A systematic review. Journal of Dermatological Treatment, 26(5), 465-470.

Akbari, J., Saeedi, M., Morteza-Semnani, K., Zarrabi, B., Rostamkalaei, S. S., \& Kelidari, H. R. (2016). The effect of Plantago major seed mucilage combined with carbopol on the release profile and bioadhesive properties of propranolol HC buccoadhesive tablets. Pharmaceutical and Biomedical Research, 2(2), 84-100.

Amini, M., Kherad, M., Mehrabani, D., Azarpira, N., Panjehshahin, M., \& Tanideh, N. (2010). Effect of Plantago major on burn wound healing in rat. Journal of Applied Animal Research, 37(1), 53-56.

Banerjee, S., Chattopadhyay, P., Ghosh, A., Pathak, M. P., Singh, S., \& Veer, V. (2013). Acute dermal irritation, sensitization, and acute toxicity studies of a transdermal patch for prophylaxis against $( \pm)$ anatoxin-A poisoning. International Journal of Toxicology, 32(4), 308-313.

Chanput, W., Mes, J. J., \& Wichers, H. J. (2014). THP-1 cell line: An in vitro cell model for immune modulation approach. International Immunopharmacology, 23(1), 37-45.

Chiang, L. C., Chiang, W., Chang, M. Y., \& Lin, C. C. (2003). In vitro cytotoxic, antiviral and immunomodulatory effects of Plantago major and Plantago asiatica. American Journal of Chinese Medicine, 31(2), 225-234.

Chiang, L. C., Chiang, W., Chang, M. Y., Ng, L. T., \& Lin, C. C. (2002). Antiviral activity of Plantago major extracts and related compounds in vitro. Antiviral Research, 55(1), 53-62.

Gonçalves, S., \& Romano, A. (2016). The medicinal potential of plants from the genus Plantago (Plantaginaceae). Industrial Crops and Products, 83, 213-226.

Hosseinkhani, A., Falahatzadeh, M., Raoofi, E., \& Zarshenas, M. M. (2017). An evidencebased review on wound healing herbal remedies from reports of traditional Persian medicine. Journal of Evidence-Based Complementary \& Alternative Medicine, 22(2), 334-343.

Houghton, P., Hylands, P., Mensah, A., Hensel, A., \& Deters, A. (2005). In vitro tests and ethnopharmacological investigations: Wound healing as an example. Journal of Ethnopharmacology, 100(1-2), 100-107.

Hussan, F., Mansor, A. S., Hassan, S. N., Kamaruddin, T. N. E., Tasnim, T. N., Budin, S. B., \& Othman, F. (2015). Anti-inflammatory property of Plantago major leaf extract reduces the inflammatory reaction in experimental acetaminophen-induced liver injury. Evidence-based Complementary and Alternative Medicine, 2015.

Ikeda, Y., Murakami, A., \& Ohigashi, H. (2008). Ursolic acid: An anti- and proinflammatory triterpenoid. Molecular Nutrition \& Food Research, 52(1), 26-42.

Jarić, S., Kostić, O., Mataruga, Z., Pavlović, D., Pavlović, M., Mitrović, M., \& Pavlović, P. (2018). Traditional wound-healing plants used in the Balkan region (southeast Europe). Journal of Ethnopharmacology, 211, 311-328.

Jivad, N., Bahmani, M., \& Asadi-Samani, M. (2016). A review of the most important medicinal plants effective on wound healing on ethnobotany evidence of Iran. Der Pharmacia Lettre, 8(2), 353-357.

Kartini, K., Fitriani, E. W., \& Tansridjata, L. (2018). Formulation and physical stability test of oleanolic acid cream and gel. Pharmaciana, 8(1), 77-86.
Kartini, Islamie, R., \& Handojo, C. S. (2018a). Wound healing activity of aucubin on hyperglycemic rat. Journal of Young Pharmacists, 10(2Suppl), s136-s139.

Kartini, Piyaviriyakul, S., Siripong, P., \& Vallisuta, O. (2014). HPTLC simultaneous quantification of triterpene acids for quality control of Plantago major L. and evaluation of their cytotoxic and antioxidant activities. Industrial Crops and Products, $60,239-246,0$.

Kartini, Piyaviriyakul, S., Thongpraditchote, S., Siripong, P., \& Vallisuta, O. (2017). Effects of Plantago major extracts and its chemical compounds on proliferation of cancer cells and cytokines production of lipopolysaccharide-activated THP-1 macrophages. Pharmacognosy Magazine, 13(51), 393-399.

Kolak, U., Boğa, M., Urușak, E. A., \& Ulubelen, A. (2011). Constituents of Plantago major subsp. intermedia with antioxidant and anticholinesterase capacities. Turkish Journal of Chemistry, 35(4), 637-645.

Kuonen, R., Weissenstein, U., Urech, K., Kunz, M., Hostanska, K., Estko, M., Heusser, P., \& Baumgartner, S. (2013). Effects of lipophilic extract of Viscum album L. and oleanolic acid on migratory activity of NIH/3T3 fibroblasts and on HaCat keratinocytes. Evidence-based Complementary and Alternative Medicine, 2013.

Liu, J. (1995). Pharmacology of oleanolic acid and ursolic acid. Journal of Ethnopharmacology, 49(2), 57-68.

Lukova, P., Karcheva-Bahchevanska, D., Nikolova, M., Iliev, I., \& Mladenov, R. (2017). Comparison of structure and antioxidant activity of polysaccharides extracted from the leaves of Plantago major L., P. media L. and P. lanceolata L. Bulgarian Chemical Communications, 49, 282-288.

Mansor, A. S., Budin, S. B., \& Othman, F. (2014). Effect of Plantago major extract on plasma cytokine changes in paracetamol-induced liver injury. Cytokine, 70(1), 49.

Mazzutti, S., Riehl, C. A., Ibañez, E., \& Ferreira, S. R. (2017). Green-based methods to obtain bioactive extracts from Plantago major and Plantago lanceolata. The Journal of Supercritical Fluids, 119, 211-220.

Moura-Letts, G., Villegas, L. F., Marçalo, A., Vaisberg, A. J., \& Hammond, G. B. (2006). In vivo wound-healing activity of oleanolic acid derived from the acid hydrolysis of Anredera diffusa. Journal of Natural Products, 69(6), 978-979.

Najafian, Y., Hamedi, S. S., Farshchi, M. K., \& Feyzabadi, Z. (2018). Plantago major in traditional Persian medicine and modern phytotherapy: A narrative review. Electronic Physician, 10(2), 6390.

Niknam, R., Ghanbarzadeh, B., Ayaseh, A., \& Rezagholi, F. (2020). The hydrocolloid extracted from Plantago major seed: Effects on emulsifying and foaming properties. Journal of Dispersion Science and Technology, 41(5), 667-673.

OECD. (2015). OECD Guideline for testing of chemicals. Acute dermal irritation/corrosion, series on testing and assessment (No. 404). Paris: Organisation for Economic Cooperation and Development.

Ozaslan, M., Didem Karagoz, I., Kalender, M. E., Kilic, I. H., Sari, I., \& Karagoz, A. (2007). In vivo antitumoral effect of Plantago major L. extract on Balb/C mouse with Ehrlich ascites tumor. American Journal of Chinese Medicine, 35(5), 841-851.

Patel, S., Srivastava, S., Singh, M. R., \& Singh, D. (2019). Mechanistic insight into diabetic wounds: Pathogenesis, molecular targets and treatment strategies to pace wound healing. Biomedicine \& Pharmacotherapy, 112, Article 108615.

Phipps, M., \& Mahmood, A. (2006). Gastroprotective activity of $P$. major in rats. International Journal of Tropical Medicine, 1(1), 36-39.

Poor, M. H. S., Khatami, M., Azizi, H., \& Abazari, Y. (2017). Cytotoxic activity of biosynthesized Ag nanoparticles by Plantago major towards a human breast cancer cell line. Rendiconti Lincei, 28(4), 693-699.

Prakash, V., Bisht, H., \& Prasad, P. (2011). Altitudinal variation in morpho-physiological attributes in Plantago major: Selection of suitable cultivation site. Research Journal of Medicinal Plant, 5(3), 302-311.

Ringbom, T., Segura, L., Noreen, Y., Perera, P., \& Bohlin, L. (1998). Ursolic acid from Plantago major, a selective inhibitor of cyclooxygenase-2 catalyzed prostaglandin biosynthesis. Journal of Natural Products, 61(10), 1212-1215.

Samuelsen, A. B. (2000). The traditional uses, chemical constituents and biological activities of Plantago major L. A review. Journal of Ethnopharmacology, 71(1-2), 1-21.

Samuelsen, A. B., Paulsen, B. S., Wold, J. K., Otsuka, H., Yamada, H., \& Espevik, T. (1995). Isolation and partial characterization of biologically active polysaccharides from Plantago major L. Phytotherapy Research, 9(3), 211-218.

Shirley, K. P., Windsor, L. J., Eckert, G. J., \& Gregory, R. L. (2017). In vitro effects of Plantago major extract, aucubin, and baicalein on Candida albicans biofilm formation, metabolic activity, and cell surface hydrophobicity. Journal of Prosthodontics, 26(6), 508-515.

Stenholm, A., Goransson, U., \& Bohlin, L. (2013). Bioassay-guided supercritical fluid extraction of cyclooxygenase-2 inhibiting substances in Plantago major $\mathrm{L}$. Phytochemical Analysis, 24(2), 176-183.

Tam, J. C. W., Lau, K. M., Liu, C. L., To, M. H., Kwok, H. F., Lai, K. K., Lau, C. P., Ko, C. H., Leung, P. C., \& Fung, K. P. (2011). The in vivo and in vitro diabetic wound healing effects of a 2-herb formula and its mechanisms of action. Journal of Ethnopharmacology, 134(3), 831-838.

Vasconcelos, M. A. L., Royo, V. A., Ferreira, D. S., Crotti, A. E. M., e Silva, M. L. A., Carvalho, J. C. T., Bastos, J. K., \& Cunha, W. R. (2006). In vivo analgesic and anti inflammatory activities of ursolic acid and oleanoic acid from Miconia albicans (Melastomataceae). Zeitschrift für Naturforschung C, 61(7-8), 477-482.

Velasco-Lezama, R., Tapia-Aguilar, R., Román-Ramos, R., Vega-Avila, E., \& PérezGutiérrez, M. S. (2006). Effect of Plantago major on cell proliferation in vitro. Journal of Ethnopharmacology, 103(1), 36-42. 
Zubair, M., Ekholm, A., Nybom, H., Renvert, S., Widen, C., \& Rumpunen, K. (2012). Effects of Plantago major L. leaf extracts on oral epithelial cells in a scratch assay. Journal of Ethnopharmacology, 141(3), 825-830.

Zubair, M., Nybom, H., Lindholm, C., Brandner, J. M., \& Rumpunen, K. (2016)

Promotion of wound healing by Plantago major L. leaf extracts - Ex-vivo experiments confirm experiences from traditional medicine. Natural Product Research, 30(5), $622-624$.

Zubair, M., Nybom, H., Lindholm, C., \& Rumpunen, K. (2011). Major polyphenols in aerial organs of greater plantain (Plantago major L.), and effects of drying temperature on polyphenol contents in the leaves. Scientia Horticulturae, 128(4), 523-529. 


$$
\underset{\text { by Sulistyo johan }}{\text { 1-S20-_1.PDF }}
$$

Submission date: 08-May-2021 09:31AM (UTC+0700)

Submission ID: 1581060547

File name: 1-S20-_1.PDF (8.25M)

Word count: 6869

Character count: 36451 


\title{
Wound healing effects of Plantago major extract and its chemical compounds in hyperglycemic rats
}

\author{
Kartini Kartini ${ }^{\text {a, }}$, Nina Wati ${ }^{\text {a }}$, Rabbindra Gustav ${ }^{a}$, Risa Wahyuni ${ }^{a}$, Yosua Fernaldi Anggada ${ }^{a}$, \\ Risna Hidayani $^{\mathrm{a}}$, Antoni Raharjo ${ }^{\mathrm{a}}$, Ridho Islamie ${ }^{\mathrm{b}}$, Sulistyo Emantoko Dwi Putra ${ }^{\mathrm{c}}$
}

a Department of Pharmaceutical Biology, Faculty of Pharmacy, University of Surabaya, Surabaya, 60293, Indonesia

b Deparment of Clinical and Community Pharmacy, Faculy of Pharmacy, University of Surabaya, Surabaya, 60293, Indonesia

${ }^{\mathrm{C}}$ Department of Biology, Faculty of Biotechnology, University of Surabaya, Surabaya, 60293, Indonesia

\section{A R T I C LE I N F O}

\section{Keywords:}

Plantago major

Greater plantain

Ursolic acid

Oleanolic acid

Diaberic

\section{A B S T R A C T}

Impaired wound healing is among the serious complications of diabetes that can lead to amputation and even death. Plantogo major has been used empirically to improve wound healing. The main bioactive compounds of P. major extracts, ursoli $53 \mathrm{~d}$ (UA) and oleanolic acid (OA), have also been studied for their benefits with nonhyperglycemic wounds. This study was done to examine the in vivo wound healing effects of $P$. major leaf extracts (PMLE), UA, and OA in hyperglycemic rats, to evaluate their in vitro diabetic wound healing activity, and to observe possible dermal irritation after topical application. Wound closure, duration of epithelialization, and histopathological profiles of healed tissue were observed in the hyperglycemic rats with excision wounds for 21 days. An anti-inflammatory test using the NO inhibitory assay, a fibroblast proliferation assay, and a migration assay with high-glucose medium were done to investigate the mechanism of action of the tested samples in wound healing. The acute dermal irritation test followed the international guidelines. PMLE, UA, and OA increased the percentage of wound closure and accelerated wound healing time. PMLE activities were assessed for the inhibition of NO production in the inflammation phase and enhancement of fibroblast proliferation. UA may contribute to this wound healing process through inhibition of NO production, whereas OA through activation of migration of fibroblast cells. Topical applications of PMLE, UA, and OA did not cause acute dermal irritation. PMLE, UA, and OA have the potential to improve wound healing with diabetes conditions.

\section{Introduction}

Plantago major or greater plantain is the most widely used species of the genus Plantago and belongs to the Plantaginaceae family. In many parts of the world, P. major is ubiquitous and, therefore, has various local names, including daun sendok in Indonesia (Adom et al., 2017; Gonçalves \& Romano, 2016; Kartini et al., 2017; Samuelsen, 2000). They are wild plants that have good adaptability to diverse conditions in the environment. Nevertheless, to minimize the exploitation of natural resources, prior studies have attempted to optimize its cultivation, harvest, and postharvest processing (Prakash et al., 2011; Zubair et al. 2011). These practices can promote sustainable and efficient production now that there is an increasingly high demand for $P$. major, both in the nutraceutical and pharmaceutical sectors.

Plantago major contains high concentrations of mucilaginous carbohydrates that are active as immunostimulants and antioxidants and are important as excip 52 ints in food processing, tablets and emulsions formulations (Akbari et al., 2016; Lukova et al., 2017; Niknam et al., 2020). Its mucilaginous property underlies the use of $P$. major as a nutraceutical, especially to improve intestinal health (Gonçalves \& Romano, 2016; Samuelsen, 2000; Samuelsen et al., 1995). In some regions, fresh leaves of $P$. major are also used as ingredients in salads and soups, and the seeds can also be processed into snacks, cakes, and breads (Gonçalves \& Romano, 2016). The medicinal properties 55 major are attributable to its various biologically active compounds such as terpenoids, ph 28 lic acids, flavonoids, alkaloids, and iridoids. It is traditionally used in the treatm 39 of a number of diseases, such as wounds and other skin diseases, infectious diseases, problems concerning the digestive and respiratory organs, reproduction and circulation issues, and tumors, and for pain relief and fever reduction (Adom et al., 2017; Goncalves \& Romano, 2016; Najafian et al., 2018; Samuelsen, 2000). Man 17 udies have been carried out to confirm these practical applications (Chiang et al., 2002, 2003; Kartini et al., 2014; Kolak et al., 2011; Mansor et al., 2014;

\footnotetext{
Corresponding author.

E-mail address kartini@staff.ubaya.ac.id (K. Kartini).
}

https://doi.org/10.1016/j.fbio.2021.100937

Received 24 June 2020; Received in revised form 21 February 2021; Accepted 22 February 2021

Available online 27 February 2021

2212-4292/C 2021 Elsevier Ltd. All rights reserved. 


\author{
Abbreviations \\ DFU diabetic foot ulcer \\ HPTLC high performance thin layer chromatography \\ NO nitric oxide \\ OA oleanolic acid \\ OECD Organisation for Economic Cooperation and \\ Development \\ PMLE Plantago major leaves extract \\ UA ursolic acid
}

\section{Ozaslan et al., 2007; Poor et al., 2017).}

These lead to the conclusion that $P$. major may have promise for the management of various chronic clinical disorders, including diabetes mellitus and its complications, particularly diabetic foot ulcers (DFU). Abdulghani et al. (2014) foun 48 at $P$. major methanol extracts at 500 and $1000 \mathrm{mg} / \mathrm{kg}$ bw lowered blood glucose levels in streptozotocin-induced diabetic rats. The mechanism underlying this activity was studied by increasing the control of the glycemic mechanism of the remaining pancreatic cells in diabetic rats (Abdulghani et al., 2014; Adom et al., 2017). P. major also has a long history of wound healing. Many countries in Europe, Asia, and the Middle East (e.g., Iran) have long used this herb either for acute or chron 54 ounds (Adom et al. 2017; Gonçalves \& Romano, 2016; Hosseinkhani et al., 2017; Jarić et al., 2018; Jivad et al., 2016). Moreover, both in vitro and in vivo tests have been done to show the wound healing effect $11 \mathrm{P}$. major and its constituents, such as UA, OA, and aucubin (Agra et al., 2015; Amini et al., 2010; Kartin 17 al., 2018a; Moura-Letts et al., 2006; Phipps \& Mahmood, 2006; Velasco-Lezama et al., 2006; Zubair et al., 2012, 2016).

However, there has been no report on $P$. major activity for diabetic wound healing. The wound healing process involves a series of overlapping phases, $30 \mathrm{ely}$, hemostasis, inflammation, proliferation, and remodeling, that may be inhibited by the presence of oxygen free radicals, microbial infection, and high blood glucose (Houghton et al., 2005; Patel et al., 2019). Chemical or herbal medicines that can modulate one or more of those phases can be examined as candidates for wound healing agents with normal or hyperglycemic conditions. Previous studies showed that $P$. major and its phytochemicals are active anti-inflammatory, antioxidant, and antimicrobial agents (Hussan et al., 56 5; Ikeda et al.. 2008; Kartini et al.. 2014, 2017; Liu, 1995; Mazzutt. et al., 2017; Shirley et al., 26 7; Stenholm et al., 2013; Vasconcelos et al., 2006). Therefore, this study was intended to determine the in vivo wound healing effects of $P$. major extracts and chemical compounds, namely UA and $\mathrm{OA}$, in hyperglycemic rats (i), to evaluate their in vitro diabetic wound healing activity through the anti-inflammatory process, fibroblast proliferation, and fibroblast migration (ii), and to determine possible dermal irritation after topical application (iii).

\section{Materials and methods}

29

\subsection{Plant materials and chemicals}

Wholes plants of $P$. major was collected from the cultivation area of the Balai Materia Medica, Batu City, Jawa Timur Province, Indonesia in September 2016 (Global Positioning System (GPS) coordinates $7^{\circ} 52^{\prime} 2.262^{\prime \prime} \mathrm{S} 112^{\circ} 31^{\prime} 11.719^{\prime \prime} \mathrm{E} ; 875 \mathrm{~m}$ above sea level) and promptly trans $31 \mathrm{~d}$ within $1 \mathrm{~h}$ to the laboratory. Authentication of the plant was done by the Center for Traditional Medicine Information and Development, University of Surabaya, Surabaya, Indonesia, with accession certificate number: $1212 / \mathrm{D} 25 \mathrm{IX} / 2016$. UA, OA, alloxan monohydrate, methylthiazolyldiphenyl-tetrazolium bromide (MTT), and hematoxylin-eosin were obtained from Sigma Aldrich Co. (St. Louis, MO, USA), whereas absolute ethanol, toluene, acetone, formic acid,

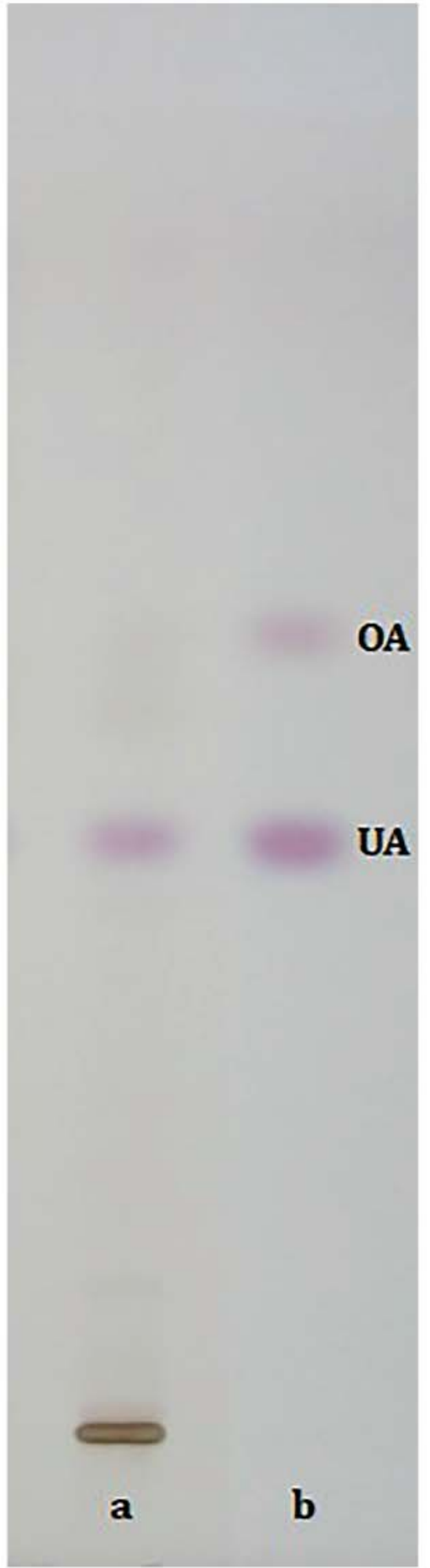

Fig. 1. High $\mathrm{p} 35$ mance thin layer chromatography profile of PMLE. Stationary phase: silica gel $60 \mathrm{~F}_{254}$, mobile phase: toluene:acetone:formic acid (78:22:0.15). a: PMLE, b: ursolic acid (UA) - oleanolic acid (OA) standard. 
K. Kartini et al. Food Bioscience 41 (2021) 100937
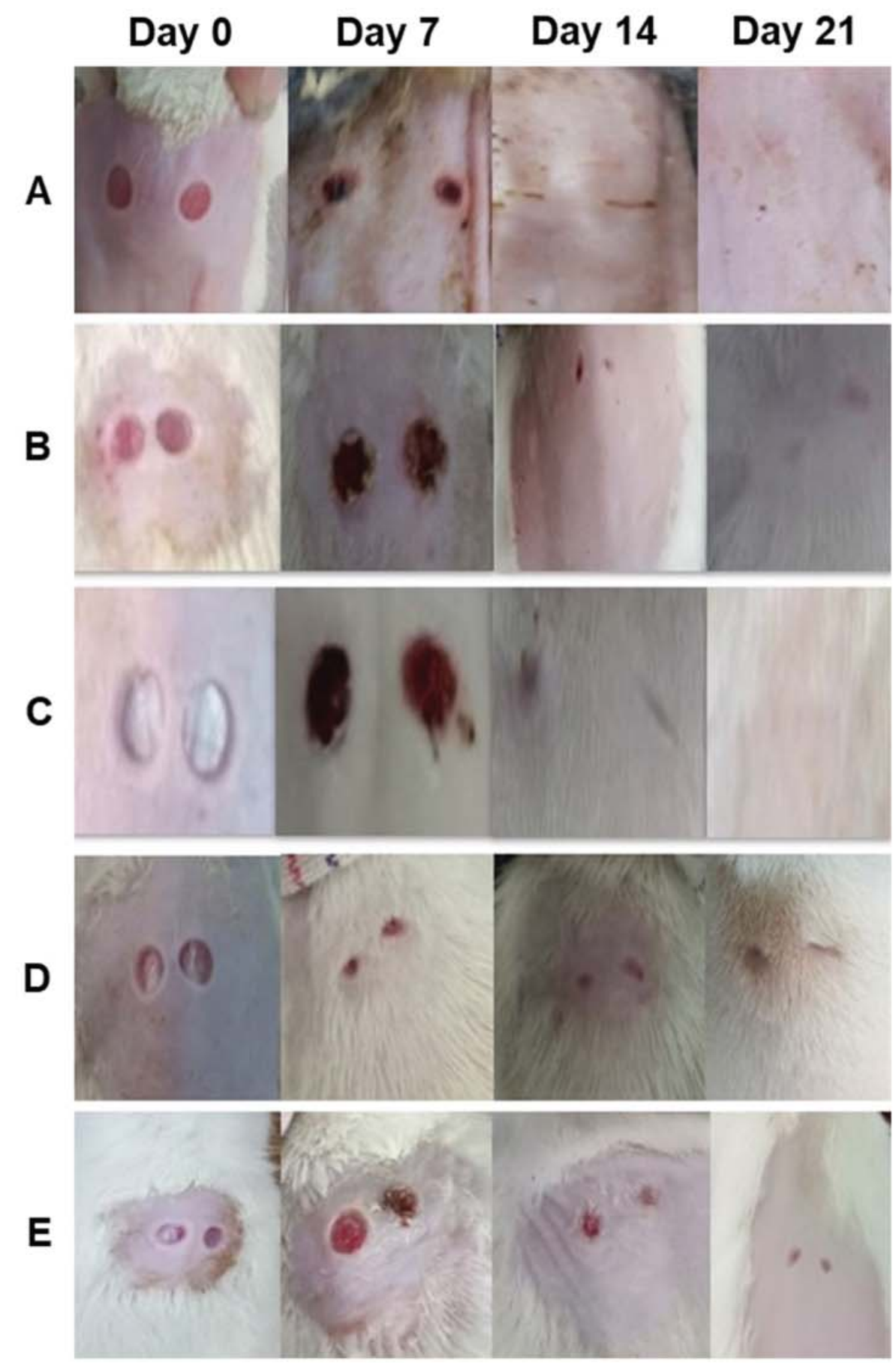

Fig. 2. Wound morphology of hyperglycemic rats from Day 0-21. A: PMLE, B: UA, C: OA, D: Positive control, E: Negative control.

sulfuric acid, methanol, chloroform, iodine, and DMSO were from Merck KGaA (Darmstadt, Germany). Carbomer, sodium hydroxide, methylIndonesia).

paraben, propylparaben, and propylene glycol were pharmaceutical grade and obtained from Tristar Chemical Co. (Surabaya, Jawa Timur, 
Table 1

Effect of gels on wound closure and time of epithelialization.

\begin{tabular}{lllll}
\hline \multirow{2}{*}{ Group } & \multicolumn{2}{l}{ Percentage of wound closure } & \multirow{2}{*}{ Time of epithelialization (day) } \\
\cline { 2 - 4 } & Day 7 & Day 14 & Day 21 & \\
\hline A & $69 \pm 3$ & $98 \pm 1$ & $100 \pm 0$ & $16 \pm 1^{*}$ \\
B & $70 \pm 3$ & $99 \pm 1^{*}$ & $100 \pm 0$ & $15 \pm 1^{*}$ \\
C & $84 \pm 8^{*}$ & $100 \pm 0^{*}$ & $100 \pm 0$ & $12 \pm 1^{*}$ \\
D & $81 \pm 6^{*}$ & $99 \pm 2$ & $100 \pm 0$ & $15 \pm 2^{*}$ \\
E & $67 \pm 2$ & $95 \pm 4$ & $100 \pm 0$ & $19 \pm 1$ \\
\hline
\end{tabular}

1.oup A: PMLE, B: UA, C: OA, D: Positive control (MeboßB), E: Negative control. Data represent means $\pm S D(n=5)$, " $p<0.05$ against negative control (KruskalWallis, followed by Mann-Whitney test).

\subsection{Preparation of $P$. major extract and determination of $U A$ and $O A$}

The leaves of $P$. major were separated from the other parts of the plant, then air-dried for $120 \mathrm{~h}$, powdered into $2 \mathrm{~mm}$ particles using a household Panasoni 11 X-J1G blender (Panasonic Corp., Kadoma, Osaka, Japan), and stored at room temperature $\left(31 \pm 2{ }^{\circ} \mathrm{C}\right)$ for a maximum of $12 \mathrm{wk}$ until used. Three hundre $37 \mathrm{~g}$ of these leaves were macerated with ethanol $(3 \times 800 \mathrm{ml}, 24 \mathrm{~h})$ at room temperature. The extracts (21) filtered using Whatman $(\mathbb{B})$ qualitative filter paper grade 1 (Merck) and evaporated under vacuum using a rotavapor R-200 (BÜCH Labortechnik AG, Flawil, Switzerland) to yield viscous extracts. High performance thin layer chromatography (HPTLC) was done to determine OA and UA as described previously (Kartini et 34 2014). Chromatography was done on a pre-coated HPTLC plate with silica gel 60 $\mathrm{F}_{254}, 0.20 \mathrm{~mm}$ layer thickness (Merck), using toluene:acetone:formic acid (78:22:0.15) as the mobile phase. PMLE and a mixture of OA and UA ( $1: 1 \mathrm{w} / \mathrm{w})$ were spotted as $5 \mathrm{~mm}$ bands using a Linomat 5 sample applicator (Camag, Muttenz, Switzerland) and then prederivatized using iodine vapor ( $1 \%$ iodine in chloroform). Development was then carried out using $10 \mathrm{ml}$ of the mobile phase in a twin trough chamber (Camag) previously equilibrated with the mobile phase for $20 \mathrm{~min}$ at room temperature. Following development, 27 plate was dried in a fume hood and subjected to derivatization by spraying the plate with $5 \%$ sulfuric acid in methanol and then heating at $120^{\circ} \mathrm{C}$ for $3 \mathrm{~min}$. The chromatogram was obtained using Reprostar 3 documentation densitometry (Camag) with a VH-C20 3CCD color video camera (Hitachi Denshi Ltd., Shinjuku City, Tokyo, Japan).

\subsection{Preparation of the gel dosage form}

P. major leaf extract (PMLE), UA, and OA were formulated into gel dosage forms as described previously using carbomer, sodium hydroxide, methylparaben, propylparaben, and propylene glycol (Kartini, et al., 2018). Carbomer ( $2 \mathrm{~g}$ ) was dispersed over $40 \mathrm{ml}$ water, stirred (1000 rpm) using a high shear mixer-HSM 2003 SV/DV (CKL Multimix (M) Sdn Bhd, Puchong, Selangor Darul Ehsan, Malaysia) while adding $1 \%$ sodium hydroxide gradually until it formed a gel. PMLE (5 g), UA $(15 \mathrm{mg})$, or OA (15 mg) were dissolved in $2 \mathrm{ml}$ ethanol. Methyl paraben $(180 \mathrm{mg})$ and propyl paraben $(20 \mathrm{mg})$ were mixed and dissolved in propylene glycol $(16 \mathrm{~g})$. These two solutions were then mixed and poured into the gel with $100 \mathrm{~g}$ water and stirred until homogeneous. The gels were administered up to $0.5 \mathrm{~g} /$ test animals. Every $0.5 \mathrm{~g}$ PMLE gel contained $25 \mathrm{mg}$ extract, whereas $0.5 \mathrm{~g}$ UA or OA gels contained $75 \mu \mathrm{g}$ of the respective active compounds.

\subsection{In vivo wound healing assay}

Male Wistar rats (180-200 g) were from the Integrated Research and Testing Laboratory, Gadjah Mada University, Yogyakarta, Indonesia and housed at room temperature, $70 \% \mathrm{RH}$, and a $12 \mathrm{~h}$ light-dark cycle. These test animals were put in plastic cages ( 1 rat/cage) and fed with a stan22 diet (water max. $13 \%$, crude protein $21-23 \%$, fat min. $5 \%$, fiber $\max .5 \%$, ash max. $7 \%$, calcium min. $0.9 \%$, and phosphorus $\min 0.6 \%$ ), given water ad libitum, and acclimatized for $2 \mathrm{wk}$ before the experiment. All handling procedures were according to the institutional rules on animal experiments (approval No: 721-KE; dated June 15, 2017). Before the $i 3$ ction of hyperglycemia, test animals were weighed, their blood was collected from the tail vein, and the fasting blood g 6 ose levels were measured. Then, they were intraperitoneally injected with a single dose of alloxan monohydrate $(160 \mathrm{mg} / \mathrm{kg}$ bw) in normal saline. Two days later, the fasting blood glucose levels were measured to confirm their hyperglycemic status. Hyperglycemia was indicated if the random blood glucose levels were $\geq 200 \mathrm{mg} / \mathrm{dl}$.

Hyperglycemic rats were intraperitoneally anesthetized with ketamine $\mathrm{HCl}$ (Ketalar $\mathbb{B}$, Pfizer Indonesia, Jakarta, Indonesia) at $100 \mathrm{mg} / \mathrm{kg}$ bw. An excision wound was induced on the dorsal area of the animals using a biopsy punch from Medax Srl 443 ersonale (San Possidonio, MO, Italy) with a diameter of $5 \mathrm{~mm}$. Test animals were then divided into 5 groups, each consisting of 5 rats. Three groups were treated with PMLE, $\mathrm{UA}$, and $\mathrm{OA}$ gels, respectively; whereas two other groups were treated with positive and negative control, respectively. A commercially available gel product containing Copitidis Rhizoma, Phellodendri chinensis

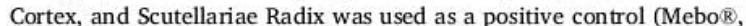
from Shantou MEBO Pharmaceutical Co., Ltd. (Shantou, Guangdong, China)), while the gel without active ingredient was applied as a negative control. All treatments were carried out topically once daily. Parameters of the in vivo wound healing were the percentage and time of wound closure. Wound diameter was measur 50 ising a digital caliper (resolution $0.01 \mathrm{~mm}$ ) on Day $0,7,14$, and 21 . The percentage of wound closure was determined using the following equation:

$\left(\left(D_{1}-D_{2}\right) / D_{1}\right) \times 100$

where $D_{1}=$ the largest wound diameter (on Day 0 ), and $D_{2}=$ wound diameter on the day of observation. Healing time was measured as the

Table 2

Effect of gels on wound healing phase on Day 21.

\begin{tabular}{ll}
\hline Group & Healing score \\
\hline A & $2.2 \pm 0.3$ \\
B & $2.7 \pm 0.0^{*}$ \\
C & $3.0 \pm 0.7^{*}$ \\
D & $3.3 \pm 0.1^{*}$ \\
E & $2.0 \pm 0.0$ \\
\hline
\end{tabular}

Group A: PMLE, B: UA, C: OA, 1 Positive control (Meboß), E: Negative control. Data represent the means $\pm S D(n=3), " p<0.05$ against negative control (Kruskal-Wallis, followed by MannWhitney test).

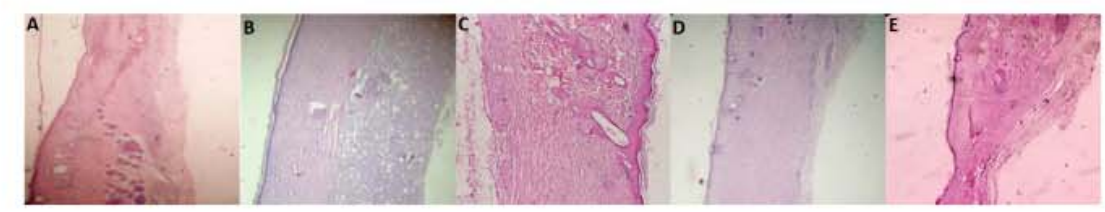

Fig. 3. Histological profiles of healing tissue on Day 21. A: PMLE, B: UA, C: OA, D: Positive control, E: Negative control. 
a

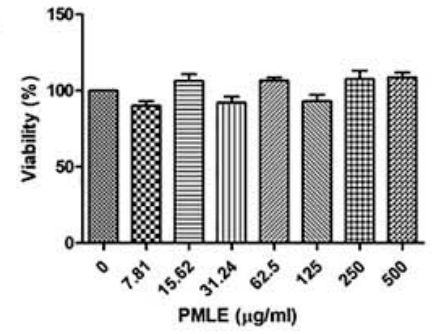

b

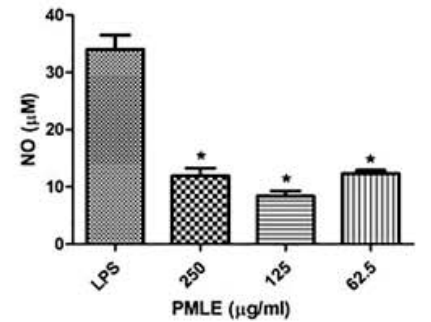

C

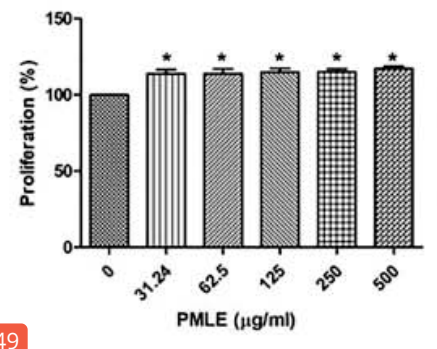

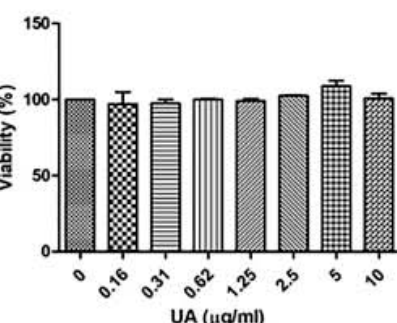
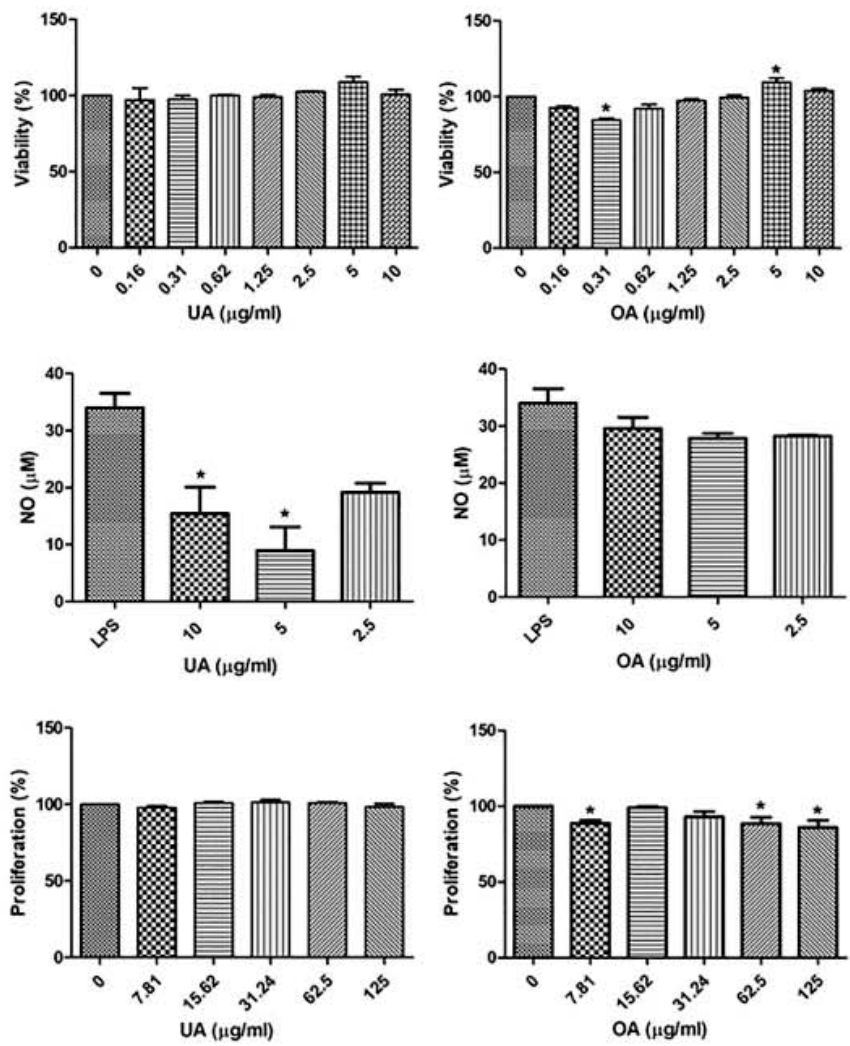

Fig. 4. The effects of PM 4, UA, and OA on the viability of the RAW 264.7 cell line (a), NO p 40 ction of RAW 264.7 cell line (b), and proliferation of NIH/3T3 fibroblast cells. Data are expressed as mean $\pm \mathrm{SD}(\mathrm{n}=3)$, " $\mathrm{p}<0.05$ against control (one-way ANOVA, followed by Tukey's multiple comparison test).

day when the wound closed fully. Also, healing tissues were collected for a histopathological study on Day 21, in which skin tissues were fixed in $10 \%$ formalin, sliced using an automatic rotary microtome (Thermo Fisher Scientific, Waltham, MA, USA) and prepared on a glass slide, stained with hematoxylin-eosin, and then observed under a light microscope (Olympus Corp., Shinjuku City, Tokyo, Japan). Histopathological study was done to evaluate the condition of healed tissue by observing the presence of inflammatory cells, angiogenesis, fibrosis, fibroblasts, and collagen, on which a score $(0-4)$ of each sample was based. Score 0 means the wound was still open. Score 1 indicated the presence of bleeding $(++)$, inflammation $(++)$, angiogenesis $(++)$, and epithelialization $(-)$; while at score 2 , there were signs of inflammation $(+)$, angiogenesis $(+)$, epithelialization $(+)$, and fibrosis $(+)$. Score 3 or early remodeling was represented by the presence of fibroblasts and collagen $(+)$, as well as epithelialization $(+)$; and score 4 or the complete remodeling phase was the formation of collagen $(++)$ and epithelialization $(++)$.

\subsection{In vitro wound healing assay}

\subsubsection{Nitric oxide (NO) inhibitory assay}

The in vitro anti-inflammatory test was done following the method used in a previous study (Tam et al., 2011). RAW264.7 cells (mouse macrophage, ATCC $\left(\right.$ TIB- $71^{\mathrm{TM}}, 4 \times 10^{5}$ /well, counted using a counting chamber with v-slash (Paul Marienfeld GmbH \& Co. KG, Lauda-Königshofen, Germany)) were seeded in a 24-well plate overnight. The cells were provided by the Parasitology Laboratory, Medical
Faculty, Gadjah Mada University. PMLE, UA, or OA were added at various concentrations together with $0.1 \mu \mathrm{g} L P S / \mathrm{ml}$ of the medium and incubated for $24 \mathrm{~h}$. The cell culture supernatant was taken out and added into Griess Reagent (Promega Corp., Madison, WI, USA) at a 1:1 ratio in 195-well plate, followed by incubation in the dark for $10 \mathrm{~min}$. The absorbance was measured at $540 \mathrm{~nm}$ using a Bio-Rad Benchmark microplate reader (Bio-Rad Laboratories Inc., Hercules, CA, USA). The $\mathrm{NaNO}_{2}$ was used to prepare a standard curve and linear regression equation.

\subsubsection{Fibroblast proliferation assay}

The procedures used for this assay were according to the method described previously, with a slight adjustment (Tam et al., 2011). $\mathrm{NIH} / 3 \mathrm{~T} 3$ cells (mouse fibroblasts, ATCC $\otimes$ CRL- $1658^{\mathrm{TM}}$; provided by the same parasitology laboratory) were seeded at $10^{3}$ cells/well in a 96-well plate in high-glucose DMEM ( $4500 \mathrm{mg} /$; Fisher Scientific International Inc., Waltham, MA, USA). Then, the cells 2 ere exposed to different concentrations of PMLE, UA, and OA for $48 \mathrm{~h}$ at $37^{\circ} \mathrm{C}$. MTT solution ( 5 $13 \mathrm{ml}$ ) in PBS (Fisher Scientific) was added to the medium in each well, and the plate was then incu $32 \mathrm{~d}$ at $37^{\circ} \mathrm{C}$ for $4 \mathrm{~h}$. All medium was then removed and replaced with DMSO. The optical density was measured at $540 \mathrm{~nm}$ to determine the relative amounts of viable cells and expressed as the percentage of control samples without treatment.

\subsubsection{Migration assay}

This test, which followed Tam et al. (2011) with adjustment for the type of cell (Tam et al., 2011), was started by seeding rat gingival 

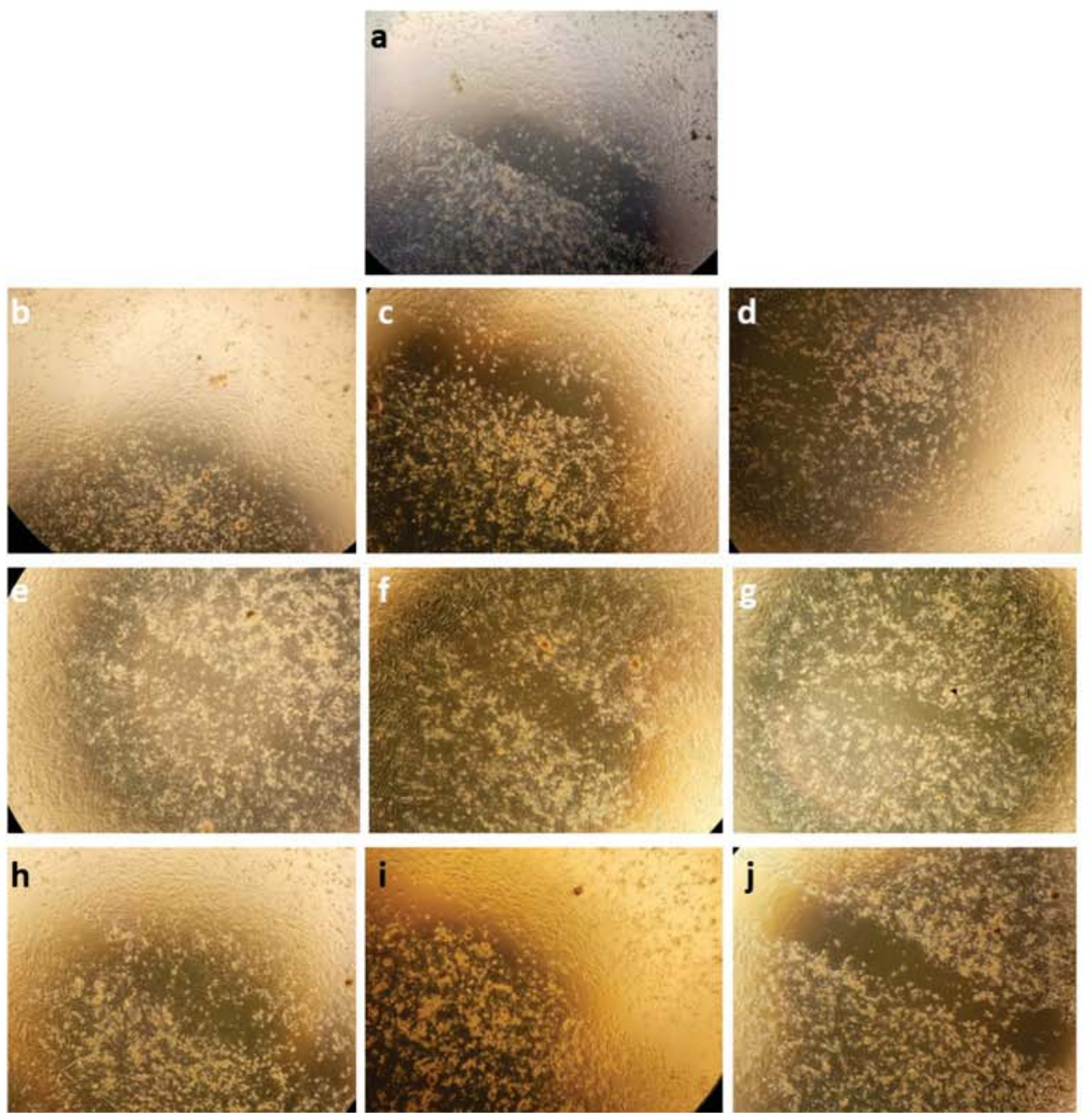

Fig. 5. Representative microphotograph of gingival fibroblast cells before the addition of the test samples (a) and after $24 \mathrm{~h}$ of incubation. b, c, d were induced with PMLE 250, 500, $1000 \mu \mathrm{g} / \mathrm{ml}$, respectively; e, f, g with UA $25,50,100 \mu \mathrm{g} / \mathrm{ml}$, respectively; h, i, j with OA $25,50,100 \mu \mathrm{g} / \mathrm{ml}$, respectively.
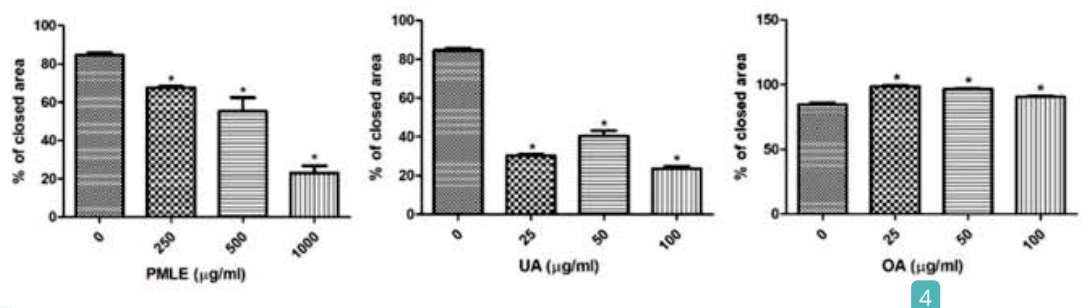

Fig. 6. The effects of $411 \mathrm{E}, \mathrm{UA}$, and $\mathrm{OA}$ on closed areas observed in the gingival fibroblast migration test on rats. Data are expressed as mean $\pm \mathrm{SD}(\mathrm{n}=3$ ), " $\mathrm{p}<0.05$ against control (one-way ANOVA, followed by Tukey's multiple comparison test).

fibroblast cells at $10^{5}$ cells/well in a 24 -well plate in high-glucose DMEM. These cells were obtained from the Insti 23 of Tropical Disease, Airlangga University (Surabaya, Indonesia). Cells were incubated for $24 \mathrm{~h}$ at $37{ }^{\circ} \mathrm{C}$ in a $5 \% \mathrm{CO}_{2}$ humidified incubator. Cells were then observed under a microscope to ensure that they had adhered to the wel and achieved a confluent state. Fibroblast cells in the well were then scratched in one direction using a $1000 \mu \mathrm{l}$ pipette tip, then observed under a light microscope, and photographs were taken. A series of concentrations of PMLE, UA, or OA solutions were added into each well, then incubated overnight. The results were observed under a light microscope and photographed. The photographs were compared and analyzed using the TScratch program (CSElab, Zurich, Switzerland) to 


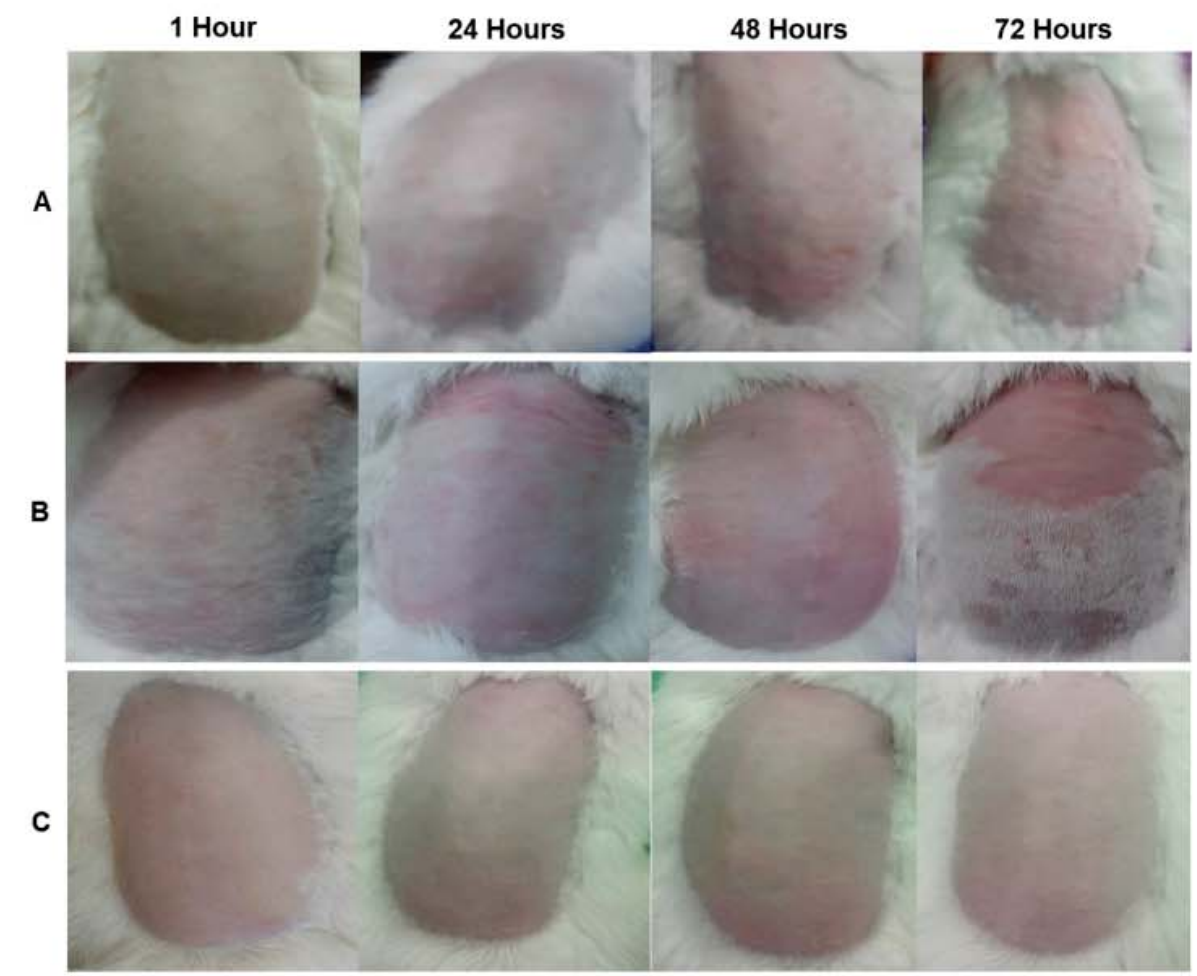

Fig. 7. The results of the 72-h acute irritation dermal test. A: PMLE, B: UA, C: OA.

10

determine the migration. This program measures open areas in the images. Percentage of the closed area before and after treatments were then calculated. An increase of the percentage of closed area indicated the migration.

\subsection{Acute dermal irritation assay}

The test followed the method recommended in the Organisation for Economic Cooperation and Development Guideline No. 404 (2015) (OECD, 2015). Healthy male albino rabbits aged 8-9 months (adult) and weighing around $1.8-2.3 \mathrm{~kg}$ were used as test animals. They were individually housed and acclimatized to the experimental conditions for $1 \mathrm{wk}$, fed with conventional laboratory diets (crude protein 18-19\%, crude fiber $13 \%$, fat $5-6 \%$, calcium $0.9 \%$, phosphorous $0.7 \%$, water $11 \%$, flumequin 5 ntibiotic and vitamins), and given ad libitum access to drinking water. Approximately $24 \mathrm{~h}$ before the test, fur was removed by carefully clipning the dorsal area of the trunk of the animals using an electrical hal 20 ipper. The test samples were applied to a small area $( \pm 6$ $\mathrm{cm}^{2}$ ) of skin and covered with a gauze pad, which was held in place with non-irritating tape (Beiersdorf Indonesia, Malang, Jawa Timur, Indonesia). For the initial test, one animal was used. Three test patches were applied sequentially to the animal. The first patch was removed after $3 \mathrm{~min}$. If there was no apparent serious skin reaction, a second patch was applied at a different site and removed after $1 \mathrm{~h}$. If the observations at this stage indicated that exposure could humanely be allowed to extend to $4 \mathrm{~h}$, a third patch was applied and removed after 4 $\mathrm{h}$, and the response was graded. If a corrosive effect appeared after any of the three sequential exposures, the test was immediately terminated. However, if no corrosive effect (irritation) was formed after the last patch was removed, the animal was observed for 14 days, unless corrosion developed at an earlier point of time. If there was no serious skin reaction in the initial test, the irritant or negative response was confirmed using up to two additional animals, each with one patch, for an exposure period of $4 \mathrm{~h}$. The animals were observed for 14 days after the removal of patches. All animals were examined for erythema and oedema, and the responses were scored at h $1,24,48$, and 72 afte 14 tch removal. Score 0 was indicated by no erythema and no oedema; score 1 was very slight erythema 14 d oedema; score 2 was well defined erythema and slight oedema; score 3 was moderate to severe erythema and moderate oedema; and score 4 was severe erythema and oedema.

\subsection{Statistical analysis}

All data were reported as mean $\pm \mathrm{SD}$, then analyzed by descriptive statistics, 0.42 vay ANOVA and Tukey's multiple comparison test in the statistical program, GraphPad Prism (GraphPad Software Inc., San Diego, CA, USA, Windows Version 5.01). If the data did not meet the requi 33 ents of a parametric statistical test, then they were processed with the Kruskal-Wallis test and the Mann-Whitney post hoc test. p < 0.05 distinguished a statistically significant difference.

\section{Results and discussion}

\subsection{High performance thin layer chromatography of PMLE}

The presence of UA and OA in the PMLE was identified using HPTLC (Fig. 1). The chromatogram showed that PMLE contains UA, but the presence of OA cannot be detected. This is consistent with the previous studies which showed that $\mathrm{OA}$ was present in the petiole, seed, and aerial parts, but not in the leaves and roots (Kartini et al., 2014, 2017). 


\subsection{In vivo wound healing}

The wound healing efficacy of PMLE, UA, and OA was investigated from the wound closure, time of epithelialization, and gross examination for 21 days. Also, at the end of the test, the histopathological profile of healed tissue was documented. Wound closure and time of epithelialization were examined to determine the rate of reduction of the unhealed area during the healing process. A faster rate of wound closure indicates a better efficacy. The shrinking of the wound area in different groups of treated animals over 21 days due to PMLE, UA, and OA is shown in Fig. 2 and Table 1.

Overall, the topical application of PMLE a 36 its chemical constituents (UA and $\mathrm{OA}$ ) increased wound closure significantly $(\mathrm{p}<0.05)$, particularly on Day 7 and 14. On Day 21, although complete wound closure was observed in all groups, no significant differences were detected. Table 1 also shows that time of epithelialization of the groups treated with PMLE and UA was not significantly different from that of the positive control (Mebo $\mathbb{B})$. It suggested that PMLE and UA are as active as the positive control. Animals treated with OA gel showed the fastest epithelialization, indicating that $\mathrm{OA}$ had higher efficacy for wound healing with hyperglycemic conditions. A previous study on wound healing in mice with normal conditions confirmed that $\mathrm{OA}$ is $42.9 \%$ faster and more effective than the placebo, and at the dose of 40 $\mu \mathrm{g} / \mathrm{g}$ bw, it produces the highest wound healing effect (Moura-Letts et al., 2006). Histological profiles of healing tissue (Fig, 3 and Table 2) show that on Day 21, animals treated with OA and positive control gels had started the remodeling phase, approaching complete remodeling. However, groups treated with PMLE, UA, and negative control were still in phase 2 and progressing to early remodeling, as characterized by ongoing angiogenesis and inflammation, and early development of fibrosis and epithelialization. These results were consistent with $\mathrm{OA}$ producing the best outcome in wound closure and the fastest epithelialization.

\subsection{Effect of PMLE, UA, OA on NO production by RAW264.7 cells}

Repair needs the coordination of various cells, growth factors, and cytokines. In diabetic patients, the normal wound healing process is interrupted by high blood gluc 15 Diabetic wounds show a persistent inflammatory phase resulting in the inhibited formation of mature granulation tissue and reduction in wound tensile strength, which may be caused by ischemic damage to blood vessels (Patel et al., 2019).

The anti-inflammatory activity of PMLE, UA, and OA was investigated using the NO inhibition test on RAW264.7 macrophage cells. The cells were cultured in high-glucose medium to mimic a diabetic condition. Apart from RAW264.7, macrophage-like cells such as THP-1 can also be used to evaluate in vitro anti-inflammatory activity. These 47 nocytes will differentiate into macrophage after induction with phorbol 12-myristate 13-acetate (PMA) (Chanput et al., 2014). The use of RAW264.7 cells was preferred since this research did not need to differentiate the cells. Bacterial infections or immunological stimuli such as LPS induce macrophages to release a high concentration of NO, which is potentially cytotoxic and can destroy the surrounding cells and tissues. Before the NO inhibition test, the effects of PMLE, UA, and OA on cell viability was evaluated to determine the appropriate concentration for the NO inhibition tests (Fig. 4a). The viability of RAW264.7 cells did not significantly decrease after the addition of PMLE, UA, and OA at up to 500,10 , and $10 \mu \mathrm{g} / \mathrm{ml}$, respectively. These results indicated that all samples at these concentrations were non-toxic to the cells and did not affect the regular cellular activity.

After treatment with PMLE, UA, and OA, the NO concentration in the cell culture media was measured using the Griess Reaction. All co 24 centrations of PMLE and UA suppressed the NO production in RAW264.7 cells significantly after LPS induction (Fig. 4b), indicating that PMLE and UA have anti-inflammatory properties. OA $(2.5-10 \mu \mathrm{g} /$ $\mathrm{ml}$ ) also inhibited the production of NO; however, the reduction was not significantly different from that of the control. On the other hand, previous research with normal media show 45 hat $\mathrm{OA}$ inhibited some inflamma 44 mediators, such as COX-2, TNF- $\alpha$, IL- $1 \beta$, IL-6, and IFN- $\gamma$ (Kartini et al., 2014, 2017; Ringbom et al., 1998; Stenholm et al., 2013). Therefore, further studies are needed to confirm whether or not $\mathrm{OA}$ is an active anti-inflammatory agent with hyperglycemic conditions using these other inflammatory mediators.

\subsection{Effects of PMLE, UA, and $O A$ on NIH/3T3 fibroblast proliferation}

The wound healing cascade is a complex interaction of cellular and bi 9 emical actions that differentiates into several phases, from healing to structural and functional integrity restoration to regain the strength of injured tissues. Fibroblast proliferation is one crucial step in tissue regeneration. A series of PMLE, UA, and OA concentrations were tested at the proliferation phase using NIH/3T3 fibroblast cells. Fig. 4c shows that PMLE at $31-500 \mu \mathrm{g} / \mathrm{ml}$ increased fibroblast proliferation, but the opposite was true for UA and OA administered at 7.8 $4625 \mu \mathrm{g} / \mathrm{ml}$. These results were consistent with Kuonen et al. that the lipophilic extract of Viscum album L. and oleanolic acid did not produce any proliferationstimulating effects in NIH/3T3 fibroblast cells at any concentration (0.01-100 and 0.001-10 $\mu \mathrm{g} / \mathrm{ml}$, respectively) (Kuonen et al., 2013). Therefore, UA and OA probably contributed to diabetic wound healing through other mechanisms.

\subsection{Effects of PMLE, UA, and $O A$ on fibroblast migration}

Angiogenesis, another process contributing to wound healing, is important until the terminal stages of healing. Its mechanism involves proliferation, migration, and remodeling of endothelial cells, followed by subsequent tube formation. The effects of PMLE, UA, and OA on the migration activity were assessed using gingival fibroblast cells that had been isolated from the rats. Fig. 5 shows the photograph of the scratched cells before the addition of the samples. This figure also shows the open area of cells at the bottom of wells after incubation with serial concentrations of PMLE, UA, and OA. Fig. 6 shows that all concentrations of PMLE and UA did not increase cell migration; on the other hand, open areas were reduced as OA concentration increased. The percentage of closed area in treated cells to the control cells indicates the level of cell migration activity. Fig. 6 shows that $\mathrm{OA}(25-100 \mu \mathrm{g} / \mathrm{ml})$ can increase the migration of rat gingival fibroblast cells.

\subsection{Acute dermal irritation test}

The results of the acute dermal irritation test of PMLE, UA, and OA gels are shown in Fig. 7. 18 dermal responses, including erythema or oedema, were found in animals treated with either UA or OA gels. In the group treated with PMLE gel, some rabbits showed erythema after 48 and $72 \mathrm{~h}$. However, this is still included in the nonirritant category (Banerjee et al., 2013).

\section{Conclusions}

Plantago major leaf extracts and its phytochemicals (UA and OA) can increase the percentage of wound closure and accelerate wound healing time in hyperglycemic rats. The extent of these activities was determined using the inhibited NO production in the inflammation phase and enhanced fibroblast proliferation. While UA contributed to the wound healing process by inhibiting NO production, OA showed the same function by activating fibroblast cell migration. Topical applications of P. major leaf extracts, UA, and OA in gel dosage forms did not cause acute dermal irritation. This study showed that $P$. major leaf extracts, $\mathrm{UA}$, and $\mathrm{OA}$ acid have the potential to improve wound healing with diabetes conditions. 


\section{Author statement}

This study was designed, directed and coordinated by Kartini Kartini, Ridho Islamie and Sulistyo Emantoko Dwi Putra for all aspects of the project. Nina Wati, Rabbindra Gustav, and Risa Wahyuni partly contributed to the in vivo wound healing assay, whereas Yosua Fernald Anggada, Risna Hidayani, and Antoni Raharjo involved in the in vitro assay and safety evaluation. Ridho Islamie and Sulistyo Emantoko Dwi Putra suggested and commented on the design of the experiments. The manus 3 pt was written by Kartini Kartini and commented by all authors. All authors have read and approved the final version of the manuscript.

\section{Declaration of competing interest}

The authors confirm that they have no conflicts of interest with respect to the work described in this manuscript.

\section{Acknowledgements}

This research was supported by the Indonesian Ministry of Research, Technology, and Higher Education (grant number 017/SP-Lit/LPPM01/Ristekdikti/FF/III/2018)

\section{References}

Abdulghani, M. A., Hamid, L, Al-Naggar, R. A., \& Osman, M. T. (2014). Potential antidiabetic activity of Piantago major leaves extract in streptozocin-induced diabetic rats. Research Joumal of Pharmaceurical, Biological and Chemical Sciences, 5(2), 896-902.

Adom, M. B., Taher, M., Mutalabisin, M. F., Amri, M. S., Kudos, M. B. A., Sulaiman, M. W. A. W., Sengupta, P., \& Susanti, D. (2017). Chemical constituents and medical benefits of Plantago majar. Biomedicine \& Pharmacotherapy, 96 , and medical $348-360$.

Agra, L. C., Ferro, J. N., Barbosa, E. T., \& Barretb, E. (2015). Triterpenes with healing activity: A systematic review, Joumal of Dermatological Treament, 26(5), 465-470. kbari, J., Saeedi, M., Morteza-Semnani, K., Zarrabi, B, Rostamkalaei, S. S., \&

Kelidari, H. R. (2016). The effect of Plantago major seed mucilage combined with carbopol on the release profile and bioadhesive properties of propranolol HCl carbopol on the release profite and bio achesive properties of propranotol thel

Amini, M., Kherad, M., Mehrabaní, D., Azarpira, N., Panjehshahin, M., \& Tanideh, N. (2010). Effect of Plantago major on burn wound healing in rat. Joumal of Applied Animal Research. 37(1), 53-56.

Banerjee, S., Chattopadhyay, P., Ghosh, A., Pathak, M. P., Singh, S., \& Veer, V. (2013). Acute dermal irritation, sensitization, and acute toxicity studies of a transdermal patch for prophylaxis against $( \pm)$ anatoxin-A poisoning. Intemational Joumal of Toxicology, 32(4), 308-313.

Chanput, W., Mes, J. J., \& Wichers, H. J. (2014). THP-1 cell line An in viro cell model for immune modulation approach. Intemational immunopharmacology, 23(1), 37-45.

Chiang, L. C., Chiang, W., Chang, M. Y., \& Lin, C. C. (2003). In viro cytotoxic, antiviral and immunomodulatory effects of Plantago major and Plantago asianica. American Joumal of Chinese Medicine, 31(2), 225-234.

Chiang, L. C., Chiang, W., Chang, M. Y., Ng, L. T., \& Lin, C. C. (2002). Antiviral activity of Plantago major extracts and related compounds in vitro. Antiviral Research, 55(1), 53-62

Gonçalves, S., \& Romano, A. (2016). The medicinal potential of plants from the genus Plantago (Plantaginaceae). Industrial Crops and Products, 83, 213-226.

Hosseinkhani, A., Falahatzadeh, M., Raoofi, E., \& Zarshenas, M. M. (2017). An evidencebased review on wound healing herbal remedies from reports of traditional Persian medicine. Journal of Evidence-Based Compiementary \& Altermative Medicine, 22(2), 334-343.

Houghton, P., Hylands, P., Mensah, A., Hensel, A., \& Deters, A. (2005). In virro tests and ethnopharmacological investigations. Wound healing as an example. Joumal of Exंnophamacology, 100(1-2), 100-107.

Hussan, F., Mansor, A. S., Hassan, S. N., Kamaruddin, T. N. E., Tasnim, T. N., Budin, S. B., \& Othman, F. (2015). Anti-inflammatory property of Plantago major leaf extract reduces the inflammatory reaction in experimental acetaminophen-induced lives injury. Evidence-based Complementary and Altemative Medicine, 2015.

Ikeda, Y., Murakami, A., \& Ohigashi, H. (2008). Ursolic acid: An anti- and proinflammatory triterpenoid. Molecular Nutrinion \& Food Research, 52(1), 26-42.

Jarič, S., Kostic, O., Mataruga, Z., Pavlović, D., Pavlovic, M., Mitrović, M., \& Pavlovič, P. (2018). Traditional wound healing plants used in the Balkan region (southeast Europe), Journal of Ethnopharmacology, 211, 311-328.

Jivad, N., Bahmani, M., \& Asadi-Samani, M. (2016). A review of the most important medicinal plants effective on wound healing on ethnobotany evidence of Iran. Der Phamacia Lerore, 8(2), 353-357.

Kartini, K. Fitriani, E. W. \& Tansridjata, L. (2018), Formulation and physical stability test of oleanolic acid cream and gel. Phamaciana, $8(1), 77-86$.
Kartini, Islamie, R., \& Handojo, C. S. (2018a). Wound healing activity of aucubin on hyperglycemic rat. Joumal of Young Phamaciss., 10(2Suppl), s136-s139.

Kartini, Piyaviriy akul, S., Siripong, P., \& Vallisuta, O. (2014). HPTLC simulaneous quantification of triterpene acids for quality control of Plantago major $\mathrm{L}$, and evaluation of their cytotoxic and antioxidant activities. Indussrial Crops and Products, $60,239-246,0$

Kartini, Piyaviriyakul, S., Thongpraditchote, S., Siripong, P., \& Vallisuta, O. (2017). Effects of Plantago major extracts and its chemical compounds on proliferation of cancer cells and cytokines production of lipopolysaccharide-activated THP-1 macrophages. Pharmacognosy Magaxine, 13(51), 393-399.

Kolak, U., Boğa, M., Urușak, E. A., \& Ulubelen, A. (2011). Constituents of Plantago major subsp, intermedia with antioxidant and anticholinesterase capacities. Turkish, Journal of Chemistry, 35(4), 637-645.

Kuonen, R., Weissenstein, U., Urech, K., Kunz, M., Hostanska, K., Estko, M., Heusser, P., \& Baumgartner, S. (2013), Effects of lipophilic extract of Viscum aibum L. and oleanolic acid on migratory activity of NIH/3T3 fibroblasts and on HaCat keratinocytes. Evidence-based Complementary and Altemative Medicine, 2013.

Liu, J. (1995). Pharmacology of oleanolic acid and ursolic acid. Joumal of Edinopharmacology $492(2), 57-68$.

Lukova, P., Karcheva-Bahchevanska, D., Nikolova, M., Iliev, L., \& Mladenov, R. (2017). Comparison of structure and antioxidant activity of polysaccharides extracted from the leaves of Plantago major L., P. media L. and P. lanceolata L. Bulgarian Chemical Communications, $49,282-288$.

Mansor, A. S., Budin, S. B., \& Othman, F. (2014). Effect of Plantago majar extract on plasma cytokine changes in paracetamol-induced liver injury. Cytokine, $70(1), 49$

Mazzutti, S., Riehl, C. A., Ibaniez, E., \& Ferreina, S. R. (2017), Green-based methods to obtain bioactive extracts from Plantago major and Plantago lanceolara. The Joumal of Supercrinical Fiuids, 119, 211-220

Moura-Letts, G., Villegas, L. F., Marçalo, A., Vaisberg, A. J., \& Hammond, G. B. (2006). In vivo wound-healing activity of oleanolic acid derived from the acid hydrolysis of Anredera diffusa. Joumal of Nanural Products, 69(6), 978-979.

Najafian, Y., Hamedi, S. S., Farshchi, M. K., \& Feyzabadi, Z. (2018). Plantago major in traditional Persian medicine and modern phytotherapy: A narrative review. Electronic Physician, $10(2), 6390$

Niknam, R., Ghanbarzadeh, B., Ayaseh, A., \& Rezagholi, F. (2020). The hydrocolloid extracted from Plantago major seed: Effects on emulsifying and foaming propertie. Journal of Dispersion Science and Technology, 41(5), 667-673.

OECD. (2015). OECD Guideline for testing of chemicals. Acute dermal irritation/corrosion, series on testing and assessment (No. 404). Paris: Organisation for Economic Cooperation and Development.

Ozaslan, M., Didem Karagoz, L., Kalender, M. E, Kilic, I. H., Sari, L., \& Karngoz, A. (2007) In vivo antitumoral effect of Plantago major L. extract on Balb/C mouse with Ehrlich ascites tumor. American Joumal of Chinese Medicine, 35(5), 841-851.

Patel, S., Srivastava, S., Singh, M. R. \& Singh, D. (2019). Mechanistic insight into diabetic wounds: Pathogenesis, molecular targets and treatment strategies to pace wound healing. Biamedicine \& Phamacotherapy, 112, Article 108615.

Phipps, M., \& Mahmood, A. (2006). Gastroprotective activity of $P$, major in rats. International Journal of Tropical Medicine, 1(1), 36-39.

Poor, M. H. S., Khatami, M., Azizi, H., \& Abazari, Y. (2017). Cytotoxic activity of biosynthesized Ag nanoparticles by Plantago major towards a human breast cancer cell line. Rendiconti Lincei, 28(4), 693-699.

Prakash, V., Bisht, H., \& Prasad, P. (2011). Altitudinal variation in morpho-physiological attributes in Plantago major: Selection of suitable cultivation site. Research. Joumal of Medicinal Plant, 5(3), 302-311.

Ringbom, T., Segura, L., Noreen, Y., Perera, P., \& Bohlin, L. (1998), Ursolic acid from Plantago major, a selective inhibitor of cyclooxygenace-2 catalyzed prostaglandin biosynthesis, Joumal of Natural Products, 61(10), 121 2-1215.

Samuelsen, A. B. (2000). The traditional uses, chemical constituents and biological activities of Plantapo major L. A review. Joumal of Em hinophammacology, 7l(1-2), 1-21. Sumuelsen, A. B., Paulsen, B. S. Wold, J. K. Otsuka, H. Yamada, H., \& Espevik, T. (1995). Isolation and partial characterization of biologically active polysaccharides from Plantago major L. Phytotherapy Research, $9(3), 211-218$.

Shirley, K. P., Windsor, L. J., Eckert, G. J., \& Gregory, R. L. (2017). In vitro effects of Plantago major extract, aucubin, and baicalein on Candida albicans biofilm formation, Plantago major extract, aucubin, and baicalein on Candida albicans biofilm formation,
metabolic activity, and cell surface hydrophobicity. Journal of Prosthodantics, 26(6),
$508-515$.

Stenholm, A., Goransson, U., \& Bohlin, L. (2013). Bioassay-guided supercritical fluid extraction of cyclooxygenase-2 inhibiting substances in Plantago major $\mathrm{L}$. Phyrochemical Analysis, 24(2), 176-183.

Tam, J. C. W. Lau, K. M. Liu, C. L., To, M. H., Kwok, H. F., Lai, K. K., Lau, C. P., Ko, C. H. Leung, P. C. \& Fung, K. P. (2011). The in vivo and in viro diabetic wound healing effects of a 2-herb formula and its mechanisms of action. Jaumal of Ethnopharmacology, 134(3), 831-838.

Vasconcelos, M. A. L, Royo, V. A. Ferreira, D. S, Crotti, A E. M., e Silva, M. L. A. Carvalho, J. C. T. Bastos, J. K. \& Cunha, W. R. (2006). In vivo analgesic and antiinflammatory activities of ursolic acid and oleanoic acid from Miconia albicans (Melastomataceae). Zeirschrift für Natufforschung C, 61(7-8), 477-482.

Velasco-Lezama, R. Tapia-Aguilar, R, Román-Ramos, R., Vega-Avila, E.. \& PérezGutierrez, M. S. (2006). Effect of Plantago major on cell proliferation in viro. Journal of Eithopharmacology, 103(1), 36-42. 


\section{K. Kartini et al.}

Zubair, M., Ekholm, A., Nybom, H., Renvert, S., Widen, C., \& Rumpunen, K. (2012), Effects of Plantago major $\mathrm{L}$. leaf extracts on oral epithelial cells in a scratch assay. Joumal of Etrnopharmacology, 141(3), 825-830.

Zubair, M. Nybom, H., Lindhoim, C., Brandner, J. M., \& Rumpunen, K. (2016). Promotion of wound healing by Plantago major L. leaf extracts - Ex-vivo experiments
Food Bioscience $41(2021) 100937$

confirm experiences from traditional medicine. Natural Product Research, 30(5), $622-624$.

Zubair, M., Nybom, H., Lindholm, C., \& Rumpunen, K. (2011). Major polvphenois in aerial organs of greater plantain (Plantago major L.), and effects of drying temperature on polyphenol contents in the leaves. Scientia Horriculturue, 128(4), $523-529$. 


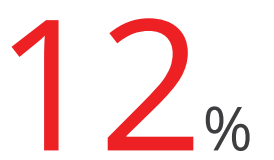

SIMILARITY INDEX

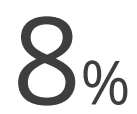

INTERNET SOURCES

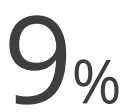

PUBLICATIONS

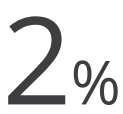

STUDENT PAPERS

PRIMARY SOURCES

1 atvb.ahajournals.org

2 Nathalie Alépée, Marie-Hélène Grandidier, José Cotovio. "Usefulness of the EpiSkin" ${ }^{\mathrm{TM}}$ reconstructed human epidermis model within Integrated Approaches on Testing and Assessment (IATA) for skin corrosion and irritation", Toxicology in Vitro, 2019 Publication

3 Zeineb Mzoughi, Hatem Majdoub. "Pectic polysaccharides from edible halophytes: Insight on extraction processes, structural characterizations and immunomodulatory potentials", International Journal of Biological Macromolecules, 2021 Publication

4 Zhang, Qi, Chi Chun Fong, Wai Kin Yu, Yao Chen, Fan Wei, Chi Man Koon, Kit Man Lau, Ping Chung Leung, Clara Bik San Lau, Kwok Pui Fung, and Mengsu Yang. "Herbal formula Astragali Radix and Rehmanniae Radix 
exerted wound healing effect on human skin fibroblast cell line Hs27 via the activation of transformation growth factor (TGF- $\beta$ ) pathway and promoting extracellular matrix (ECM) deposition", Phytomedicine, 2012. Publication

5 G.P. Dillon, A. Yiannikouris, C.A. Moran. "Toxicological evaluation of a glycan preparation from an enzymatic hydrolysis of Saccharomyces cerevisiae", Regulatory Toxicology and Pharmacology, 2021 Publication

6 Riazul Haque Tuhin, Mst. Marium Begum, Md. Sohanur Rahman, Rubaba Karim et al. "Wound healing effect of Euphorbia hirta linn.

(Euphorbiaceae) in alloxan induced diabetic rats", BMC Complementary and Alternative Medicine, 2017 Publication

7 mdpi.com

8 Submitted to Bronx High School of Science

9 Rupesh Thakur, Nitika Jain, Raghvendra Pathak, Sardul Singh Sandhu. "Practices in Wound Healing Studies of Plants", EvidenceBased Complementary and Alternative Medicine, 2011 
10 Www.oecd.org

11 livrepository.liverpool.ac.uk

14 Ah, Y.C.. "A novel transdermal patch incorporating meloxicam: In vitro and in vivo characterization", International Journal of Pharmaceutics, 20100129 Publication

Satish Patel, Shikha Srivastava, Manju Rawat Singh, Deependra Singh. "Mechanistic insight into diabetic wounds: Pathogenesis, molecular targets and treatment strategies to pace wound healing", Biomedicine \&

Pharmacotherapy, 2019 Publication

16 Submitted to Universitas Sebelas Maret 
20 www.fs.fed.us

21 Kotíková, Zora, Miloslav Šulc, Jaromír

Lachman, Vladimír Pivec, Matyáš Orsák, and

Karel Hamouz. "Carotenoid profile and

retention in yellow-, purple- and red-fleshed

potatoes after thermal processing", Food

Chemistry, 2016.

Publication

Monika Lazarová, Juraj Lábaj, Peter Eckl,

Grigorij Kogan, Darina Slameňová. "Effects of

Dietary Intake of a Fungal $\beta$-D-Glucan

Derivative on the Level of DNA Damage

Induced in Primary Rat Hepatocytes by

Various Carcinogens", Nutrition and Cancer,

2006

Publication

23 Submitted to Queen Mary and Westfield College

Ziwen Liu, Yumei Fan, Yu Wang, Cui Han, Yu Pan, Huang Huang, Ying Ye, Lan Luo, Zhimin Yin. "Dipyrithione inhibits lipopolysaccharide- 
induced iNOS and COX-2 up-regulation in macrophages and protects against endotoxic shock in mice", FEBS Letters, 2008 Publication

25 Dong-Kyoo Kim, Jin Hyen Baek, Chang-Mo Kang, Mi-Ae Yoo et al. "Apoptotic activity of ursolic acid may correlate with the inhibition of initiation of DNA replication", International Journal of Cancer, 2000 Publication

26

Elaine Reina, Nouf Al-Shibani, Eman Allam, Karen S. Gregson, Michael Kowolik, L. Jack Windsor. "The Effects of Plantago major on the Activation of the Neutrophil Respiratory Burst", Journal of Traditional and Complementary Medicine, 2013 Publication

27 Min Jung Kwon, He Min Shin, Haribalan Perumalsamy, Xue Wang, Young-Joon Ahn. "Antiviral effects and possible mechanisms of action of constituents from Brazilian propolis and related compounds", Journal of Apicultural Research, 2019 Publication

Fatima Benaoun, Cédric Delattre, Zakaria Boual, Alina V. Ursu et al. "Structural 
characterization and rheological behavior of a heteroxylan extracted from Plantago notata

Lagasca (Plantaginaceae) seeds",

Carbohydrate Polymers, 2017

publication

30 Kumar, B.. "Ethnopharmacological

approaches to wound healing-Exploring

medicinal plants of India", Journal of

Ethnopharmacology, 20071101

Publication

31

Nina Dewi Oktaviyanti, Kartini, Abdul Mun'im.

"Application and optimization of ultrasound-

assisted deep eutectic solvent for the

extraction of new skin-lightening cosmetic

materials from Ixora javanica flower", Heliyon,

2019

Publication

32 Thongchai Taechowisan, Chunhua Lu,

Yuemao Shen, Saisamorn Lumyong. "Anti-

inflammatory Effects of 4-Arylcoumarins in

LPS-induced Murine Macrophage RAW 264.7

Cells", Pharmaceutical Biology, 2008

Publication

33 app.trdizin.gov.tr

Internet Source

$<1 \%$

tel.archives-ouvertes.fr 
36 "Poster Presentation - Others : Abstract",

Respirology, 2014.

37 Adetutu, A.. "Ethnopharmacological survey

and in vitro evaluation of wound-healing

plants used in South-western Nigeria", Journal

of Ethnopharmacology, 20110901

Publication

38 Luming Wan, Huan Yang, Huilong Li, Jing Gong et al. "GP73 is a glucogenic hormone regulating SARS-CoV-2-induced

hyperglycemia", Cold Spring Harbor

Laboratory, 2021

Publication

39

Samuelsen, A.B.. "The traditional uses,

chemical constituents and biological activities

of Plantago major L. A review", Journal of

Ethnopharmacology, 200007

Publication

40 brage.bibsys.no 
43 scitepress.org

44 theses.gla.ac.uk

Internet Source

45 Www.carahealth.com

46 www.journal.uad.ac.id

47 www.repository.cam.ac.uk

48 www.semanticscholar.org

49 Furtado, R. A., E. P. Rodrigues, F. R. R. Araujo, W. L. Oliveira, M. A. Furtado, M. B. Castro, W.

R. Cunha, and D. C. Tavares. "Ursolic Acid and Oleanolic Acid Suppress Preneoplastic Lesions Induced by 1,2-Dimethylhydrazine in Rat Colon", Toxicologic Pathology, 2008. Publication

Zahra Zamani, Seyed M.A. Razavi.

"Physicochemical, rheological and functional properties of Nettle seed (Urtica pilulifera) gum", Food Hydrocolloids, 2020 Publication

ejournal.uin-malang.ac.id 
52 eprints.skums.ac.ir

54 revistas.ufcg.edu.br

55 Ahmed F. Al-obaidi. "Chapter 7 Phytotoxicity of Extracts on Germination and Seedling Growth of Purslane ( ) ", IntechOpen, 2020 Publication 